\title{
¿Validation of a High-Resolution Numerical Weather Prediction Land Surface Scheme Using Catchment Water Balances
}

\author{
Daniel Regenass, ${ }^{\mathrm{a}}$ Linda Schlemmer, ${ }^{\mathrm{b}}$ Oliver Fuhrer, ${ }^{\mathrm{c}}$ JeAn-MARie Bettems, \\ MARCO ARPAGAUS, ${ }^{c}$ AND CHRISTOPH SCHÄR ${ }^{\mathrm{a}}$ \\ ${ }^{\mathrm{a}}$ Institute for Atmospheric and Climate Science, ETH Zurich, Zurich, Switzerland \\ ${ }^{\mathrm{b}}$ Deutscher Wetterdienst, Offenbach, Germany \\ ${ }^{\mathrm{c}}$ Federal Office of Meteorology and Climatology MeteoSwiss, Zurich, Switzerland
}

(Manuscript received 16 November 2020, in final form 10 July 2021)

\begin{abstract}
An adequate representation of the interaction between the land surface and the atmosphere is critical for both numerical weather prediction and climate models. The surface energy and mass balances are tightly coupled to the terrestrial water cycle, mainly through the state of soil moisture. An inadequate representation of the terrestrial water cycle will deteriorate the state of the land surface model and introduce biases to the atmospheric model. The validation of land surface models is challenging, as there are very few observations and the soil is highly heterogeneous. In this paper, a validation framework for land surface schemes based on catchment mass balances is presented. The main focus of our development lies in the application to kilometer-resolution numerical weather prediction and climate models, although the approach is scalable in both space and time. The methodology combines information from multiple observation-based datasets. Observational uncertainties are estimated by using independent sets of observations. It is shown that the combination of observation-based datasets and river discharge measurements close the water balance fairly well for the chosen catchments. As a showcase application, the framework is then applied to compare and validate four different versions of TERRA ML, the land surface scheme of the COSMO numerical weather prediction and climate model over five mesoscale catchments in Switzerland ranging from 105 to $1713 \mathrm{~km}^{2}$. Despite large observational uncertainties, validation results clearly suggest that errors in terrestrial storage changes are closely linked to errors in runoff generation and emphasize the crucial role of infiltration processes.

SIGNIFICANCE STATEMENT: Soil water shapes the response of the land surface to solar radiation. On scales on the order of several kilometers (which are relevant to weather prediction and regional climate modeling) it is hard-if not impossible - to compare model output with direct measurements of soil water. However, in catchments, due to mass conservation, we know that soil water change is related to three terms: precipitation, evapotranspiration (soil evaporation and plant transpiration), and river discharge at the outlet. We present a framework with which these terms can be assessed on the level of medium-sized catchments. When applying this framework to our own model, we find that model errors in soil water change are likely caused by errors in infiltration and runoff generation.
\end{abstract}

KEYWORDS: Atmosphere-land interaction; Water budget/balance; Land surface model; Model evaluation/performance; Numerical weather prediction/forecasting; Regional models

\section{Introduction}

The atmosphere is permanently exchanging moisture, energy, and momentum with the land surface. This interaction may be characterized on various spatiotemporal scales from individual convective events (Hohenegger et al. 2009; Rihani et al. 2015; Imamovic et al. 2017) to climate (Seneviratne et al. 2010). The importance of an accurate representation of the land surface has been recognized from early on in the history of atmospheric modeling (e.g., Manabe et al. 1965). More recently, linkages between soil moisture and both surface temperature (Schär et al. 2004; Vidale et al. 2007; Fischer et al. 2007;

\footnotetext{
D Denotes content that is immediately available upon publication as open access.
}

Corresponding author: Daniel Regenass, daniel.regenass@env. ethz.ch
Mueller and Seneviratne 2012; Schumacher et al. 2019) and precipitation (Pielke 2001; Hohenegger et al. 2009; Taylor et al. 2013; Leutwyler et al. 2021) have been established. The moisture state of the soil affects predictive skill in subseasonal forecasts (Beljaars et al. 1996; Entekhabi et al. 1999; Koster et al. 2009; Dirmeyer and Halder 2016; Koster et al. 2020).

Land surface models (LSMs) currently used for numerical weather prediction (NWP), e.g., Noah (Niu et al. 2011) and HTESSEL (Balsamo et al. 2009), typically represent hydrological and thermal processes within the soil matrix and within a vegetation layer between soil and atmosphere. The basic concepts describing these processes are similar in many land surface models. The thermal fluxes are accounted for with a $1 \mathrm{D}$ heat diffusion equation. Vertical water transport to the deeper soil is usually based on a formulation of the Richards equation (Richards 1931), which describes the flow of water in porous media. Depending on the complexity of the LSM, the vegetation layer includes only transpiration from the soil root zone to the atmosphere (e.g., the TERRA multilayer 
scheme, TERRA ML hereafter) or additionally also shading and thermal effects (see, e.g., Viterbo and Beljaars 1995). In most LSMs, the soil moisture dynamics is represented in onedimensional vertical columns, and the runoff process is represented locally, i.e., there is no explicit lateral transport of soil water between columns.

LSMs grew in complexity to today's third generation schemes, which include carbon and nitrogen cycles. An illustrative example for this growth in complexity is the Community Land Model (CLM) (Lawrence et al. 2019). While in general these developments added more realism, they also increased the model parameter space with often poorly constrained parameters (Prentice et al. 2015). Cuntz et al. (2016) report large sensitivities on the bare soil resistance parameter in Noah. Bellprat et al. (2016) showed that by modulating hydraulic conductivity in TERRA ML, it is possible to shift mean summer surface temperatures over continental Europe by more than 1-2 K. Moreover, many LSMs still rely on old lookup tables for soil thermal and hydraulic properties based on laboratory measurements, e.g., by Brooks and Corey (1966). Soil properties are not well constrained by field observations, leaving modeling communities with a large set of free parameters. Furthermore, the validation of soil processes and constraining parameters related to soil properties is challenging due to the large heterogeneity even at relatively small scales (Western et al. 2002; Vereecken et al. 2007; Chaney et al. 2015). Therefore, to ensure that LSMs do not only perform well in terms of skill score, but also in terms of a physically reasonable representation of the land surface, a carefully designed validation strategy is crucial to further improve the accuracy of LSMs.

Within the atmospheric science community, LSMs are typically validated either indirectly by considering surface meteorological variables, such as two meter temperature (see, e.g., Schlemmer et al. 2018) or explicitly by considering surface fluxes (Chen et al. 1997; Abramowitz et al. 2008; Haughton et al. 2016; Schulz and Vogel 2017). In contrast, hydrologists tend to validate their models by comparing estimated and observed discharge at river gauges (Gulden et al. 2007; Stöckli et al. 2007; Zhou et al. 2018). Considering the fact that soil moisture is a crucial variable for subseasonal to interannual feedback processes (Dirmeyer and Halder 2016; Koster et al. 2009; Seneviratne et al. 2010), an interesting approach is also to assess seasonal variations in terrestrial water storage change via catchment mass budget equations, as has been proposed by Hirschi et al. (2006). Such an approach can reveal deficiencies in different processes, and it is scalable to different catchment scales.

More recently, evapotranspiration estimates from catchment mass balances have also been used to validate evapotranspiration products in the framework of the Water Cycle Observation Multimission Strategy (WACMOS) project (Miralles et al. 2016). Cai et al. (2014) carried out a thorough hydrological evaluation of Noah-MP using (among other data) USGS streamflow measurements. However, as pointed out above, validation studies in the land surface modeling community are often carried out at point scale using eddy covariance measurements. While it is important to validate model performance in individual components of the terrestrial water cycle, these processes are tightly coupled and it may be worthwhile to develop a validation strategy which helps the modeling community to identify error sources in all components of the terrestrial water cycle and to find potential interconnections and error cancellation mechanisms in these error sources.

In this work, we present a process-oriented validation strategy for LSMs on the kilometer scale. By applying the validation framework to two versions of TERRA ML (Heise et al. 2003), the land surface model of COSMO (Baldauf et al. 2011) on a $0.01^{\circ} \times 0.01^{\circ}$ grid, we test the ability of the validation framework to diagnose model deficiencies. Thereby, we focus on two main questions. First, is it possible to draw conclusions given potentially large uncertainties in the validation datasets? Second, does our validation approach yield any added value or complementary information to point-scale and meteorological validation approaches? The remainder of this paper is organized as follows. In section 2, the model used in this study is presented and the forcing and validation datasets are introduced. In section 3, the basic ideas of the validation strategy are introduced and thoughts on spatial and temporal aggregation as well as uncertainty estimation are explained. Observation derived catchment water balances are presented in the first part of the results section (section 4) and estimates for observational uncertainty are shown in the second part. In the last and most comprehensive part of the results section, the validation framework is applied to four different versions of TERRA ML. Finally, we present our conclusions and an outlook on further applications in section 5 .

\section{Model and data}

In the first part of this section, the land surface scheme used in this study is presented. In the second part, validation datasets used for the estimation of catchment mass balances and independent datasets for uncertainty estimation will be introduced.

\section{a. The TERRA ML land surface scheme}

\section{1) GENERAL DESCRIPTION}

TERRA ML (Heise et al. 2003) is a one-dimensional multilayer land surface scheme depicting thermal and hydrological processes on the surface and in the subsurface in a highly simplified manner. Heat transport in the soil is treated with a one-dimensional heat equation, where heat capacity and conductivity of the individual layers depend on soil water content. Water transport in the soil is parameterized using the Richards equation (Richards 1931) with vertical fluxes following the formulation of Rijtema (1969), which prescribe an exponential dependence of conductivity and diffusivity on soil water content. A detailed description of soil hydraulic parameter can be found in appendix B. Surface runoff is generated by saturation and or infiltration excess and the remaining water is infiltrated into the soil. Ground runoff is produced by excess water between the layers and by gravitational drainage from the lowermost hydrological layer. Due to the one-dimensional formulation, both ground and surface runoff are diagnostic quantities that arise at the level of each individual grid point and there is no lateral exchange of water (i.e., no routing). 

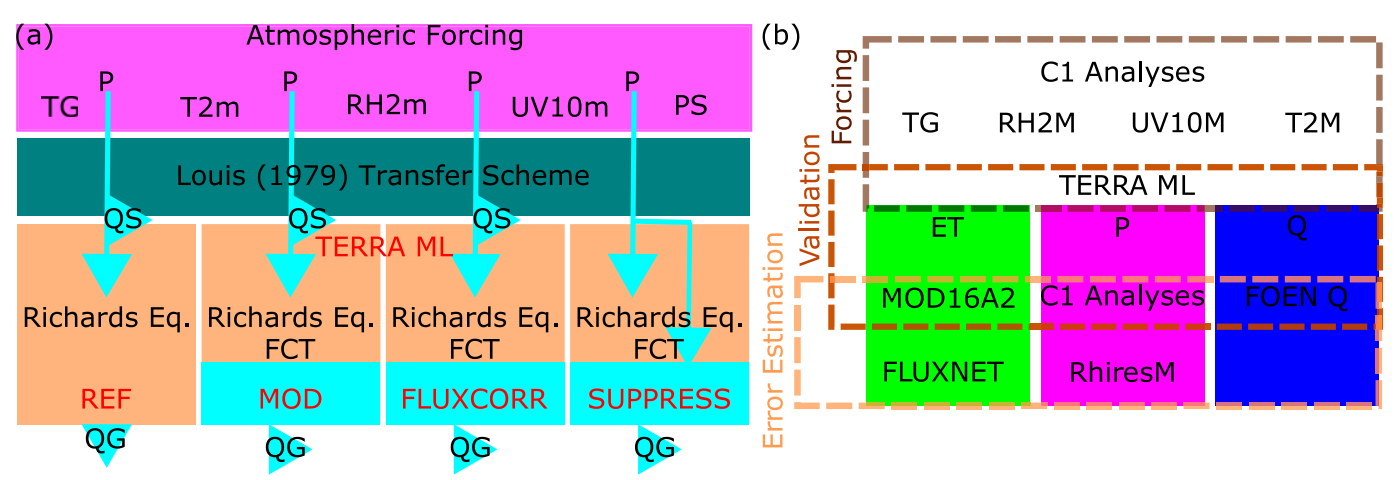

FIG. 1. (a) Overview on the TERRA ML standalone. TG is ground temperature (net radiation), T2m is $2-\mathrm{m}$ temperature, RH2m is $2-\mathrm{m}$ relative humidity, UV10 $\mathrm{m}$ is $10-\mathrm{m}$ wind, and PS is surface pressure; $P$ is precipitation, and QS and QG are surface and ground runoff, respectively. The different experiments from sections 2a(2)(i)-(iv) are indicated in red. REF is the reference version of TERRA ML, MOD contains the Schlemmer et al. (2018) groundwater model. INFIL and SUPPRESS are extensions to MOD with different treatments for infiltration. (b) Overview on the usage of forcing and validation data. $\mathrm{C} 1$ analyses are COSMO-1 analyses, MOD16A2, FOEN $\mathrm{Q}$, FLUXNET, and RhiresM are abbreviations for the other products introduced in section $2 \mathrm{~b}$. Abbreviations of variables [not appearing in (a)] are ET evapotranspiration and $Q$ river discharge.

Potential evaporation is calculated by a bulk transfer equation with transfer coefficients from the turbulence scheme. Resistances for plant transpiration and bare soil evaporation follow the formulations of Jarvis (1976) and Schulz and Vogel (2020), respectively.

The vertical discretization for both the heat equation and Richards equation has eight layers with interfaces at $0.01,0.03$, $0.09,0.27,0.81,2.43,7.29$, and $21.87 \mathrm{~m}$. The time step for the model in standalone mode for this study is $120 \mathrm{~s}$, while it is shorter (20 s at $1-\mathrm{km}$ horizontal resolution) when coupled to the full COSMO model.

\section{2) DESCRIPTION OF THE EXPERIMENTS}

In this study, four different versions of TERRA ML are compared. The first version (REF hereafter) follows the parameterization described above. The second version (MOD hereafter) incorporates a revised groundwater and runoff formulation (Schlemmer et al. 2018). During the course of this work, it is noticed that the parameterization of infiltration seems to be critical for the amount of runoff that will be produced by the model. Therefore, two more versions specifically address the formulation of infiltration excess runoff. The third version features a flux corrected transport infiltration limitation at the land-atmosphere interface (FLUXCORR hereafter), and the fourth version suppresses surface runoff completely (SUPPRESS hereafter). All experiments (simulations) are carried out on a rotated pole grid with a horizontal resolution of $0.01^{\circ} \times 0.01^{\circ}$ (roughly $1.1 \mathrm{~km}$ in both horizontal directions.), matching the resolution of the forcing data. Input from forcing data (i.e., precipitation) is given on hourly time levels and then disaggregated (split evenly) to the time step (120 s). A brief description of all tested versions is given subsequently, and a schematic overview is shown in Fig. 1a.

\section{(i) Reference version $(R E F)$}

In the reference version, the Richards equation is solved using a backward implicit scheme for the diffusive part.
The boundary conditions are given by the infiltration rate at the top and by free drainage at the bottom. The rate of drainage is thereby given by the hydraulic conductivity $K$, which depends on soil water content and a set of soil hydraulic properties (see appendix B). To account for macropores formed by roots and a higher fraction of organic matter close to the surface, the saturated hydraulic conductivity is assumed to decrease exponentially with the distance between layer interface $z$ and root depth $z_{R}$ (Decharme et al. 2006):

$$
K_{\mathrm{sat}}=K_{0} \exp \left[-f\left(z-z_{R}\right)\right]
$$

with the soil type dependent constant $K_{0}$ and a tuning parameter $f$. Here we use a value of $f=2.0$. The infiltration limitation is on the one hand given by the saturated hydraulic conductivity $K_{\text {sat }}$ at the surface and on the other hand by the available pore space in uppermost layer at the beginning of the time step. In the reference version (and only here), the hydrological part of TERRA ML only extends to the secondto-last layer interface, which corresponds to a total depth of $7.29 \mathrm{~m}$. Water leaving the vertical column at its bottom and water exceeding the field capacity is taken as groundwater runoff.

\section{(ii) An alternative groundwater and runoff formulation (MOD)}

In MOD water transport is calculated following Richards (1931) with the flux parameterizations by Rijtema (1969) and the formulation for saturated hydraulic conductivity introduced by Decharme et al. (2006) [Eq. (1)]. Additionally to the processes contained in REF, Schlemmer et al. (2018) implemented a zeroflux lower boundary condition and the gravitational part of the Richards equation is solved using a flux corrected transport scheme (FCT) for the hydraulic fluxes in order to ensure mass conservation (Boris and Book 1973; Zalesak 1979). The diffusive part of the Richards equation is again solved with a backward implicit scheme. The zero-flux boundary along with the mass conserving implementation of the Richards equation allows for a 
water table to form at the bottom of the soil column. The subsurface runoff is then diagnosed from this water table.

Usually, water flows from elevated regions to valleys and plains. There are efforts to directly account for the redistribution of water in the soil by solving the three-dimensional Richards equation (e.g., Maxwell et al. 2007; Rihani et al. 2015). Without any doubt, lateral subsurface flow is important for the distribution of groundwater and the susceptibility of a given region to drought (Maxwell and Kollet 2008), but the soil properties (i.e., macropores and preferential flow paths) are largely unknown. Furthermore, solving the three-dimensional Richards equation comes at considerable computational cost (Burstedde et al. 2018). Therefore, Schlemmer et al. (2018) choose to account for this redistribution by scaling the diagnosed ground runoff $Q$ with the subgrid-scale slope of orography $S_{\text {ORO }}$ as follows:

$$
Q=L_{g}^{-1} S_{\text {ORO }} K_{\text {sat }}\left(z_{\mathrm{wt}}\right),
$$

where $K_{\text {sat }}\left(z_{\mathrm{wt}}\right)$ is the saturated hydraulic conductivity at water table depth and $L_{g}^{-1}$ may be interpreted as the dominant length scale of subgrid-scale inhomogeneity. By parameterizing the ground runoff, the computational effort is dramatically reduced in comparison to the three-dimensional Richards equation, as the computations in the LSM remain one-dimensional.

\section{(iii) FCT-based infiltration limitation (FLUXCORR)}

In the reference version (REF) as well as in MOD, infiltration is limited by two factors. On the one hand, the maximum infiltration rate at the surface is given by $K_{\text {sat }}$ at the surface. On the other hand, a volumetric limit is given by calculating free pore space in the first layer at the beginning of the time step. It is possible that the latter limit leads to a dependence of infiltration on both time step and layer thickness. This is an unwanted effect, particularly as the time step in standalone model simulations is usually chosen larger than in coupled mode, as both thermal and hydraulic conductivity in the soil are substantially slower than processes in the atmosphere. For FLUXCORR, the volumetric limit of infiltration $I_{\max }^{n}$ is calculated following Eq. (43) in Schlemmer et al. (2018), replacing $K_{k-1 / 2}$ with volumetric infiltration rate $I$,

$$
I_{\max }^{n}=\min \left[I_{K}^{n}, \widetilde{K}_{1 / 2}^{n}+\Delta z_{1}\left(\frac{\eta-\theta_{1}^{n}}{\Delta t}-\widetilde{Q}_{1}^{n}\right)\right],
$$

where $I_{K}^{n}$ is infiltration limited by maximum hydraulic conductivity at the surface on time level $n, \widetilde{K}_{1 / 2}^{n}$ is the flux corrected conductivity at the interface between first and second layer, $\Delta z_{1}$ is layer thickness of the first layer, $\eta$ and $\theta_{1}$ are pore volume and volumetric water content, respectively, $\Delta t$ is the time step and $\widetilde{Q_{1}^{n}}$ is diagnosed ground runoff from the first layer. The underlying idea here is to use flux corrected transport (Boris and Book 1973; Zalesak 1979) consequently up to the land-atmosphere interface to avoid numerical inconsistencies. Otherwise, in terms of hydrological processes within the soil matrix, FLUXCORR is equivalent to MOD.

\section{(iv) Suppressed surface runoff (SUPPRESS)}

The motivation for SUPPRESS is given by the observation that surface runoff barely exists on scales of order $1 \mathrm{~km}$ or larger (and hence on the scales land surface schemes are typically used for NWP and regional climate research and prediction). On these scales, a formulation based solely on Darcy's law and the Richards equation seems to neglect important physical processes, i.e., conduction of water through cracks and macropores, [see, e.g., Beven and Germann (1982) for an early review on the subject]. Here, we assume that water not captured by the soil close to the surface will find its way to the water table. Therefore, surface runoff as calculated in MOD is added directly to the water table at the beginning of the time step. As is the case for FLUXCORR, in terms of hydrological processes within the soil matrix, SUPPRESS is equivalent to MOD.

\section{3) TERRA ML IN STANDALONE MODE}

A standalone version of TERRA ML is used to test the different groundwater and runoff formulations. The standalone uses TERRA ML from COSMO version 5.03 including the work of Schlemmer et al. (2018) as an additional option. The boundary conditions for the soil heat equation are provided from the analysis fields [section $2 b(1)$ ] through the temperature of the uppermost soil layer, $T_{G}$. This temperature is determined directly by the surface energy balance as the current version of TERRA ML does not have a skin or canopy temperature. This implies that a forcing with $T_{G}$ is equivalent to forcing with net radiation, i.e., any feedbacks of the soil hydrology to the thermal section and or to surface albedo cannot be assessed with the given setup (see Fig. 1a for an overview). Despite limitations, the standalone setup is an attractive choice to test new implementations as it saves a lot of computational resources on the one hand by design and on the other hand because it can be run on arbitrarily small domains (i.e., single catchments). The alternative for testing developments in the LSM at low costs would be to test coupled runs at reduced resolution. The drawback with this approach is that rainfall intensities and soil heterogeneity is likely very different at lower resolutions.

In this study, focus is mainly on storage change and runoff for the following reason: The stress factors in the resistance formulations for both bare soil evaporation and plant transpiration depend linearly on soil moisture and will therefore be altered by a change of soil water [see Schulz and Vogel (2020) and Doms et al. (2011), Eqs. (11.24)-(11.28) for details]. For instance, the soil in MOD is expected to be substantially wetter than in REF, which decreases bare soil and plant resistances. However, the response of the atmosphere is severely limited in standalone mode as the driving atmosphere does not take up the excess moisture caused by an increase in evapotranspiration. The driving moisture gradient between surface and first atmospheric layer is the same as in REF, but now there is substantially more moisture available for evapotranspiration. Therefore, evapotranspiration is likely to be overestimated for versions with substantially wetter soil than the version in the driving model (REF). Moreover, in TERRA ML, the energy balance is closed with the ground temperature after the heat fluxes are calculated, therefore, when forcing with ground temperature, there is no energy constraint on evapotranspiration. This limitation is to some extent always present when operating uncoupled land surface schemes that were originally 
TABLE 1. Overview on datasets used in this study.

\begin{tabular}{|c|c|c|c|c|c|}
\hline Name & Field & Usage & Resolution & Relation to observation & Reference \\
\hline COSMO-1 analyses & $\bar{P}, T_{G}$ & Forcing & $1 \mathrm{~km}, 1 \mathrm{~h}$ & Model with assimilated observations & Schraff and Hess (2003) \\
\hline Discharge measurements & $Q$ & Validation & Point, $1 \mathrm{~h}$ & Direct observation & FOEN (2021) \\
\hline MODIS MOD16A2 & $\tilde{\mathrm{ET}}$ & Validation & $500 \mathrm{~m}, 8$ days & $\begin{array}{l}\text { Model with assimilated } \\
\text { observations, remotely } \\
\text { sensed vegetation state }\end{array}$ & Running et al. (2017) \\
\hline RhiresM & $\bar{P}$ & $\begin{array}{l}\text { Uncertainty } \\
\text { estimation }\end{array}$ & $2 \mathrm{~km}, 1$ month & Spatially interpolated observations & MeteoSwiss (2016) \\
\hline FLUXNET 2015 & $\overline{\mathrm{ET}}$ & $\begin{array}{l}\text { Uncertainty } \\
\text { estimation }\end{array}$ & Point, $30 \mathrm{~min}$ & $\begin{array}{l}\text { Direct observations }+ \text { turbulence } \\
\quad \text { closure model }\end{array}$ & Various (see Table D2) \\
\hline
\end{tabular}

designed as part of an NWP model. The question is only whether the inconsistency arises below (as is the case for TERRA ML) or above the surface transfer scheme. The upper boundary condition for the hydrological section of the model is given by the precipitation of the forcing fields. Hence, after initialization of soil temperature and soil water content, the standalone only requires data of surface temperature and precipitation in regular intervals. The standalone outputs turbulent heat fluxes [as calculated by the Louis (1979) transfer scheme], soil water contents and temperatures for each layer as well as surface and ground runoff. The relation between TERRA ML and the forcing fields is illustrated in Fig. 1a.

Forcing data are available for the computational domain of COSMO- 1 , the formerly operational deterministic $0.01^{\circ}$ model setup at MeteoSwiss. As the standalone model effectively consists of a collection of independent one-dimensional columns, it can in principle be run over any domain. Here, the standalone is either run over the full domain or over subdomains containing the chosen catchments. In this study, a 3-yr period from 2010 to 2012 is used to force the standalone model. This period is chosen as it was not extraordinary with respect to the local climatology. Thus, a large change of the storage term is not expected over the 3 -yr period. To ensure sufficient spinup of the soil model, the period is cycled twice, and the analysis period is the third cycle, which corresponds to a spin up time of 6 years followed by a period of three years for validation/analysis. For the chosen catchments, the spinup period of 6 years is found to be sufficient to ensure the equilibration of TERRA ML (see appendix C). In this study, the TERRA ML standalone is initialized and then forced with MeteoSwiss COSMO-1 preoperational analyses [see section $2 b(1)]$ for the years 2010-12.

\section{b. Validation datasets}

In this section the datasets used in this study are introduced. An overview is given in Table 1 and the intended usage is indicated in Fig. $1 \mathrm{~b}$ and will be discussed in section $3 \mathrm{~d}$, after the validation strategy is outlined.

\section{1) COSMO-1 ANALYSES}

MeteoSwiss runs a suite of simulations with the COSMO model (Baldauf et al. 2011) over the Alpine region at various resolutions (see appendix A for a more detailed description). In this study, preoperational COSMO-1 analyses are used. At the lateral boundaries, COSMO-1 is driven by operational
ECMWF analyses. The analyses combine a first guess from the COSMO model on a $0.01^{\circ} \times 0.01^{\circ}$ horizontal grid (roughly $1 \mathrm{~km}$ ) with observations from radiosondes and aircraft through Newtonian relaxation (nudging) (Schraff and Hess 2003). Furthermore latent heat nudging is used to improve the quality of precipitation analyses and forecasts (Stephan et al. 2008). The analyses are available in hourly intervals and the computational domain can be seen in Fig. 2. The following variables are used to force the TERRA ML standalone: 2-m temperature, $10-\mathrm{m}$ wind, relative humidity at $2 \mathrm{~m}$, surface pressure, and ground temperature (Fig. 1a). Moreover precipitation is also used for the validation (Fig. 1b, discussion in section 3d).

\section{2) RHIRESM GRIDDED PRECIPITATION DATASET}

RhiresM is a monthly gridded precipitation dataset for Switzerland (MeteoSwiss 2016). The dataset is available on a $2.2-\mathrm{km}$ grid and based on typically 430 conventional rain gauge stations. The interpolation algorithm accounts for grid point elevation with a linear regression and weighs measurements according to closeness and spatial isolation with respect to the analysis point. Details of the algorithm are described in Frei and Schär (1998) and Frei and Schmidli (2006). The interpolation error as estimated by a "leave one out" cross validation is $\approx 20 \%$ in the Jura and Swiss Plateau regions and $\approx 25 \%-30 \%$ in the Alpine region. In addition, there are error contributions due to gauge undercatch ranging from $4 \%$ during summer season in the Swiss Plateau up to $40 \%$ during winter for stations above $1500 \mathrm{~m}$ above sea level (Sevruk 1985).

\section{3) RIVER DISCHARGE MEASUREMENTS}

Switzerland has a relatively dense network of river discharge measurement stations (Weingartner 1989). All measurements in this study stem from river gauges operated by the Federal Office for the Environment (FOEN). The discharge measurements used in this study are available in hourly resolution. The location of the river gauges and the corresponding catchments is shown in Fig. 2 and further information is provided in appendix D.

\section{4) MODIS MOD16A2 EVAPOTRANSPIRATION PRODUCT}

The Moderate Resolution Imaging Spectroradiometer (MODIS) MOD16A2 evapotranspiration (ET) product (Running et al. 2017) combines remotely sensed information on vegetation type and state with meteorological data obtained from NASA's 


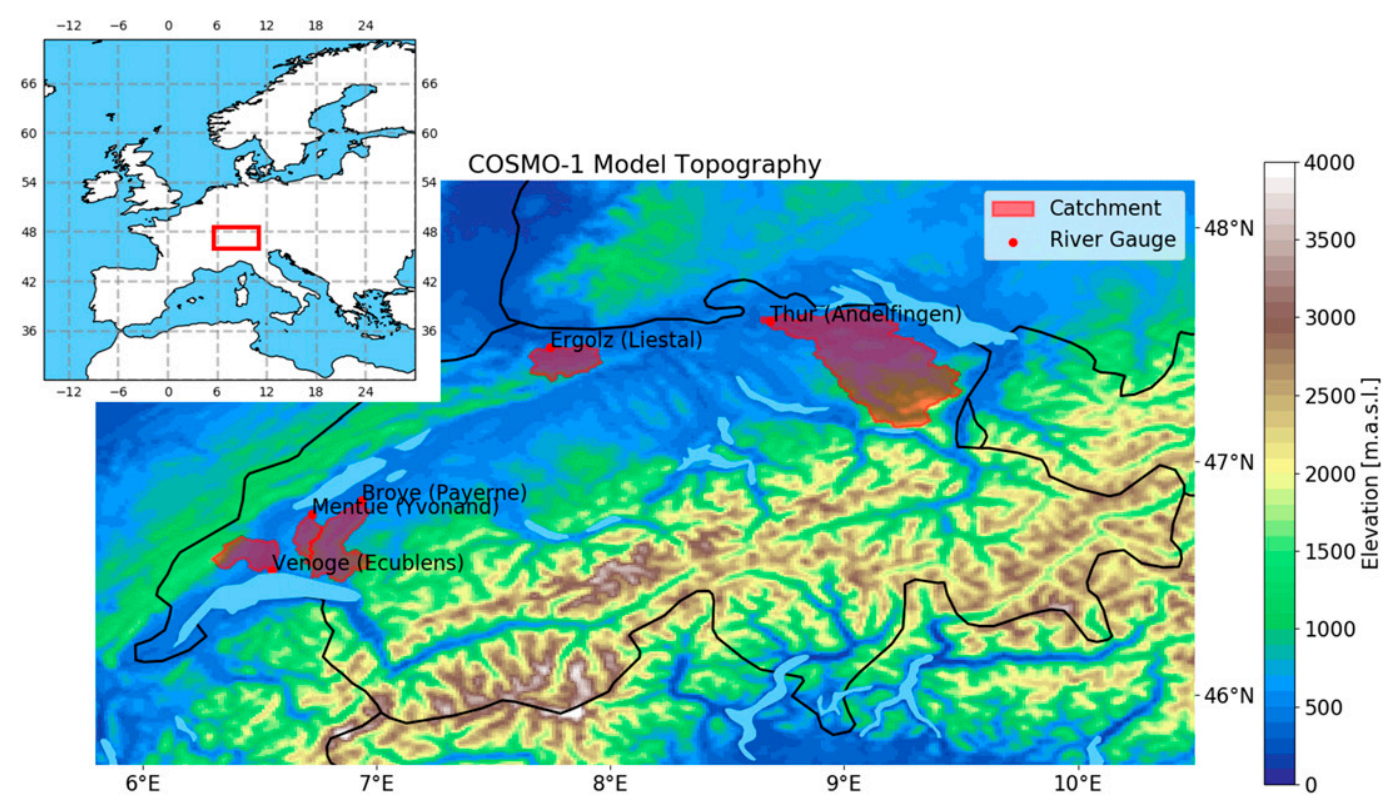

FIG. 2. Study region with catchments chosen for validation (red shaded areas) and the corresponding locations of river gauges (red dots, names in brackets). The location of the region on the European continent is shown as a red rectangle in the inlet.

Global Modeling and Assimilation Office (GMAO) in a Penman-Monteith type algorithm (Mu et al. 2011; Penman 1948). It is available on a grid of roughly $0.5 \mathrm{~km} \times 0.5 \mathrm{~km}$ with a temporal resolution of eight days. Daily meteorological forcing data are only fed to the MOD16 ET algorithm on a coarse $0.5^{\circ} \times 0.6^{\circ}$ or even $1.0^{\circ} \times 1.25^{\circ}$ grid and then interpolated nonlinearly to the $0.5-\mathrm{km}$ MODIS grid (Zhao et al. 2005, 2006). Eight days averages are then aggregated to monthly time levels by weighted averaging, where the weights for each observation are calculated by the number of days, which are fully within a given month.

\section{5) FLUXNET 2015 EVAPOTRANSPIRATION DATA}

The FLUXNET 2015 dataset is a collection of eddy-covariance measurement data from a global network (Pastorello et al. 2020). The data are uniformly gap-filled and quality-controlled as described in Pastorello et al. (2020). Here, the energy balance corrected fluxes are used, where the turbulent heat fluxes are scaled such that they close the surface energy balance, while the Bowen ratio is assumed to be correct (Foken 2008). These data are available on half-hourly and daily intervals, but only daily averages are used in this study. Ten stations in the vicinity of the validation catchments are chosen, an overview is given in Table D2 in appendix D. Data availability is different among stations, ranging from 2 to 5 years of overlap with the MODIS evapotranspiration product.

\section{Validation strategy}

In this section, the validation strategy will be outlined. First, the water balance and some fundamental assumptions are presented. Then, the temporal and spatial aggregation is discussed and the approach to uncertainty estimation is shown. Finally, a brief overview on the usage of data to close the water balance is given.

\section{a. A simplified water balance equation}

It has long been recognized that catchments-or on largerscale river basins - are a suitable spatial unit for model validation (e.g., Hirschi et al. 2006; Stöckli et al. 2007; Miralles et al. 2016) as one can formulate water conservation by means of a mass balance equation for which we will give a short derivation hereafter.

The water balance for a unit surface can be expressed by two partial differential equations describing the evolution of condensed (liquid or solid) water in the soil and on the surface. Soil water is described by the volumetric soil water content $\theta$, and is assumed to cover all water in the soil (liquid or frozen, soil moisture or groundwater). Surface water is described in units of equivalent water depth $h$ for liquid water (i.e., the depth of water in streams, lakes, interception storage, or overland flows) and for frozen water (i.e., the snow-water equivalent of snow and ice volumes), respectively. Using a downward-pointing vertical $z$ coordinate, the time evolution of soil water can be expressed as

$$
\frac{\partial \theta}{\partial t}+\nabla \cdot \mathbf{F}=0
$$

with the upper boundary condition at the $\operatorname{surface} \mathbf{F}(z=0)=$ $I-E_{\theta}$ where $I$ denotes infiltration (or exfiltration) and $E_{\theta}$ evapotranspiration of soil moisture to the overlying air column. The quantity $\mathbf{F}$ is the three-dimensional water flux in the soil (in units of $\mathrm{m} \mathrm{s}^{-1}$ ). Here, we define $\mathbf{F}$ such that it includes fluxes through the soil matrix as well as contributions by fluxes in roots (which are driven by $E_{\theta}$ at the surface). The surface water contribution is governed by 


$$
\frac{\partial h}{\partial t}+\nabla \cdot \mathbf{G}=P-E_{h}-I
$$

Here $\mathbf{G}$ is the horizontal flux of surface water (in units of $\mathrm{m}^{2} \mathrm{~s}^{-1}$ ), and it would include contributions from rivers, lakes and overland flows, but also contributions from ice and snow movements (i.e., in glaciers and avalanches). The source-sink terms $P, E_{h}$, and $I$ relate to precipitation, evaporation from surface water, and infiltration, respectively.Upon integrating Eq. (4) from the surface $(z=0)$ to bedrock $\left(z=z_{B}\right)$ one obtains

$$
\int_{0}^{z_{B}} \frac{\partial \theta}{\partial t} d z+\nabla_{h} \cdot \mathbf{F}_{h}=I-E_{\theta},
$$

where $\mathbf{F}_{h}=\int_{0}^{z_{B}} \mathbf{F} d z$ denotes the (two-dimensional) total horizontal water flux in the soil and $\nabla_{h}$ the (two-dimensional) nabla operator in the horizontal directions. The total water storage of a soil/surface water column is given by $W=\int_{0}^{z_{B}} \theta d z+h$. Upon adding (5) and (6), one obtains

$$
\frac{\partial W}{\partial t}+\nabla_{h} \cdot\left(\mathbf{F}_{h}+\mathbf{G}\right)=P-E
$$

where $E=E_{\theta}+E_{h}$ is total evapotranspiration. Averaging over a catchment with area $A$ and boundaries $\partial A$ and using Gauss' integral theorem, this is

$$
\frac{\partial \bar{W}}{\partial t}+\frac{1}{A} \oint_{\partial A}\left(\mathbf{F}_{h}+\mathbf{G}\right) \cdot \mathbf{n} d s=\bar{P}-\bar{E}
$$

where overbars denote catchment averages, e.g., $\bar{P}=1 / A \iint_{A} P d x d y$ and $\mathbf{n}$ denotes the outward pointing normal vector at the catchment boundary.

For our study, we intend to use (8) using a number of simplifications:

(i) We assume that the below-surface water fluxes across catchment boundaries can be neglected, i.e.,

$$
\oint_{\partial A} \mathbf{F}_{h} \cdot \mathbf{n} d s \approx 0
$$

This assumption appears well justified for larger catchments. In general, with increasing catchment size, the contributions from $\mathbf{F}_{h}$ become smaller, as the area of the catchment scales with $\mathrm{A}$, while the circumference of the catchment scales with $\sqrt{A}$. One important exception is flow across the catchment boundaries along the river axis. This flux is indeed hard to quantify, and we rely on trusting the river gauge to be placed at a reasonable location, where this flux can be neglected compared to the measured river discharge at the catchment outlet.

(ii) We assume that the above-surface fluxes are dominated by river discharge, i.e.,

$$
\oint_{\partial A} \mathbf{G} \cdot \mathbf{n} d s \approx Q,
$$

where $Q$ represents river discharge measured at the outlet of the catchment. This assumption is normally justified for similar reasons as (i). (iii) On catchment scale, total water storage change is approximated by its soil water contribution, i.e.,

$$
\frac{\partial \bar{h}}{\partial t} \ll \frac{\partial}{\partial t} \overline{\int_{0}^{z_{B}} \theta d z} \text { or } \frac{\partial \bar{W}}{\partial t} \approx \frac{\partial}{\partial t} \overline{\int_{0}^{z_{B}} \theta d z .}
$$

Clearly, the validity of (11) depends on the climatological and geographical characteristics of the catchments considered. For instance, if the catchment includes large lakes, or if there is a pronounced seasonal cycle in snow storage, approximation (11) will not be valid. Similarly, the validity depends upon the time scale onsidered with the temporal derivative. The approximation will be poor on daily time scale but will improve with longer (weekly to monthly) time scales.

With the above approximations, (8) becomes

$$
\frac{\partial \bar{W}}{\partial t}=\bar{P}-\bar{E}-Q .
$$

Using Eq. (12), it is possible to close the water balance if data for the individual terms are available.

In the context of land surface modeling for NWP, one is mostly concerned with evapotranspiration, as it represents an energy and moisture source for the atmosphere, and substantially affects the energy partitioning at the surface. However, river discharge strongly affects the net soil-water balance and thereby ultimately influences evapotranspiration. This is particularly the case for alpine regions such as Switzerland, where river discharge and evapotranspiration have a similar order of magnitude. It is thus helpful to trace all components of the water balance, as the error propagation might be subtle and conceptual model deficiencies are hard to detect by means of standard verification methods that focus on heat fluxes and near-surface meteorological variables. As an example, a negative bias in summer evapotranspiration might root in a surplus of spring discharge and the associated loss of water, and not merely in the formulation of evapotranspiration.

Equation (12) offers another possibility for validation: For annual to interannual time scales (typically $\geq 1$ year), storage change is negligible compared to precipitation, river discharge and evapotranspiration and Eq. (12) can be simplified and rearranged to

$$
\langle\overline{E T}\rangle=\langle\bar{P}-Q\rangle
$$

where the \langle\rangle denote long-term temporal means. Using Eq. (13) offers both the possibility to assess the quality of evapotranspiration datasets and the possibility to evaluate long-term mean evapotranspiration from model output.

\section{b. Spatial and temporal aggregation}

In the following, the targeted spatial and temporal scales of the validation strategy are outlined. In terms of temporal scale, we aim at a resolution of one month, since it allows ignoring short-term runoff processes that would require a routing scheme to connect runoff from individual LSM grid points to river discharge $Q$. Instead, using temporal aggregation and 
assumptions i and ii, we can link river discharge and runoff at the unit surface as

$$
Q \approx \iint_{A} \nabla_{h} \cdot\left(\mathbf{F}_{h}+\mathbf{G}\right) d A \Leftrightarrow \frac{Q}{A} \approx \frac{1}{A} \iint_{A} \nabla_{h} \cdot\left(\mathbf{F}_{h}+\mathbf{G}\right) d A .
$$

In the model world, $\nabla_{h} \cdot\left(\mathbf{F}_{h}+\mathbf{G}\right)$ corresponds to the diagnosed surface and ground runoff from individual LSM grid points. Therefore, Eq. (14) allows for a direct comparison of aggregated runoff and river discharge at the outlet. As the equivalence suggests, these quantities can either be expressed as units of volume per time for the aggregated runoff or as rate of change in water column for the area averaged runoff. To allow for an intuitive comparison with precipitation and evapotranspiration, the latter option is chosen in this paper. When aggregating budget terms to monthly time levels, there is a loss of valuable information. However, it is argued that a temporal resolution of one month is still high enough to trace the partitioning of water in the land surface model, which affects available soil water for evapotranspiration and thereby the surface energy balance on shorter time scales.

In terms of spatial scale, the minimum scale on which the land surface scheme should be able to give a reasonable response to the atmosphere matches the effective resolution of the atmospheric model, which is roughly 4-5 times the horizontal model grid spacing (Bierdel et al. 2012) for COSMO and 7 times the model grid spacing (Skamarock 2004) for the Weather Research and Forecasting (WRF) Model. For stateof-the-art mesoscale NWP with horizontal resolutions of one to three kilometers, this corresponds to a horizontal length scale of $7-21 \mathrm{~km}$. Given that the heterogeneity is typically larger at the surface than in the free troposphere, the effective resolution of a model might be a bit worse close to the surface. It is argued that a reasonable lower limit for the horizontal length scale of a model with $1-\mathrm{km}$ resolution is around $10 \mathrm{~km}$. As a simple land surface scheme does not include river routing, there is a trade-off between the minimum time scale that can be resolved and the maximum horizontal length scale. Given these considerations, in this study the focus of the validation is on mesoscale catchments with an area of order $100-5000 \mathrm{~km}^{2}$, and monthly time scales. An overview over the catchments considered in this study is given in appendix D, Table D1, and their geographical location is shown in Fig. 2.

In high-resolution NWP, the diurnal cycle of evapotranspiration is of great importance but cannot be addressed given the spatiotemporal constraints described above. However, our framework is suitable to quantify errors in soil water memory which affect the atmosphere on monthly to annual time scales. Therefore, this catchment-based validation is not considered to be a replacement for point-scale validation of surface energy partitioning at eddy-covariance sites, but as a complementary tool to reveal model deficiencies.

To conclude our thoughts on aggregation and scales, it should be stressed that the temporal and spatial scales are chosen such as to carry out a validation for simple land surface models on the kilometer scale. The assumption on lake and glacier storages can be relaxed if one moves to longer time scales or if the model at hand includes these storage terms. The temporal aggregation may be chosen to be much shorter if the land surface model contains a river routing scheme. Therefore-given the necessary precaution-validation with catchment balances is flexible with respect to spatial and temporal scales.

\section{c. Uncertainty estimation}

At convection-resolving scales, weather and climate models already perform well in many aspects (see, e.g., Weusthoff et al. 2010; Baldauf et al. 2011; Leutwyler et al. 2017; Ban et al. 2021). Some of the validation data used in this study are not direct observations but products that rely on the assimilation of observational data, and thereby use a set of subjective assumptions, in particular when using remotely sensed data. This is particularly the case for evapotranspiration datasets which are derived from meteorological forcing and a satellite-based remotely sensed vegetation state derived from irradiances (see, e.g., Running et al. 2017; Fisher et al. 2008; Martens et al. 2017). These two points necessitate a rough estimation of uncertainty, which will be outlined in this section. In essence, the monthly uncertainty is estimated from differences between different datasets.

Let us assume that we are able to calculate the root mean squared error (RMSE) for the individual terms of the RHS of Eq. (12). The terms $\Delta \bar{P}, \Delta Q$, and $\Delta \overline{\mathrm{ET}}$ are RMSEs of precipitation, discharge/aggregated runoff and evapotranspiration, respectively. All these terms are assumed to apply to monthly data. For river discharge, there are direct measurements with high spatial and temporal resolution available (which is not the case for precipitation and evapotranspiration). It is therefore reasonable to assume that $\Delta Q \ll \Delta \bar{P}, \Delta \overline{\mathrm{ET}}$. Furthermore assuming $\Delta \bar{P}$ and $\Delta \overline{\mathrm{ET}}$ are independent on monthly time scales, the RMSE of storage change may be estimated by means of Gaussian error propagation,

$$
\Delta \frac{d \bar{W}}{d t}=\sqrt{\Delta \bar{P}^{2}+\Delta \overline{\mathrm{ET}}^{2}}
$$

Formally, $\Delta \bar{P}$ and $\Delta \overline{\mathrm{ET}}$ are given by the RMSE between validation datasets and an additional (independent) dataset. For the sake of clarity, we will refer to $\Delta \bar{P}, \Delta \overline{\mathrm{ET}}, \Delta Q$ and $\Delta(d \bar{W} / d t)$ as uncertainties, while error will hereafter be the expression for the (monthly) difference between model output and validation dataset. The estimation of $\Delta \bar{P}, \Delta Q$ and $\Delta \overline{\mathrm{ET}}$ is discussed in section $4 \mathrm{~b}$. The uncertainty in storage change, $\Delta(d \bar{W} / d t)$ is then calculated with these estimates following Eq. (15).

While the uncertainty of the river discharge measurement itself is negligible compared to $\Delta \bar{P}$ and $\Delta \overline{\mathrm{ET}}$, the uncertainty in precipitation directly propagates to catchment averaged runoff as precipitation from the MeteoSwiss COSMO-1 analyses are also used to force the model. Therefore, when comparing modeled runoff and observed discharge, we give $\Delta Q_{M}=\Delta \bar{P}$ as a rough uncertainty estimate. Note that this is not an observational uncertainty and therefore it has not to be included in the error propagation when calculating the uncertainty in storage change [Eq. (15)].

\section{d. Usage of data to close the water balance}

A full overview over all datasets used in this study is given in Table 1 and a schematic overview on the usage is given in 

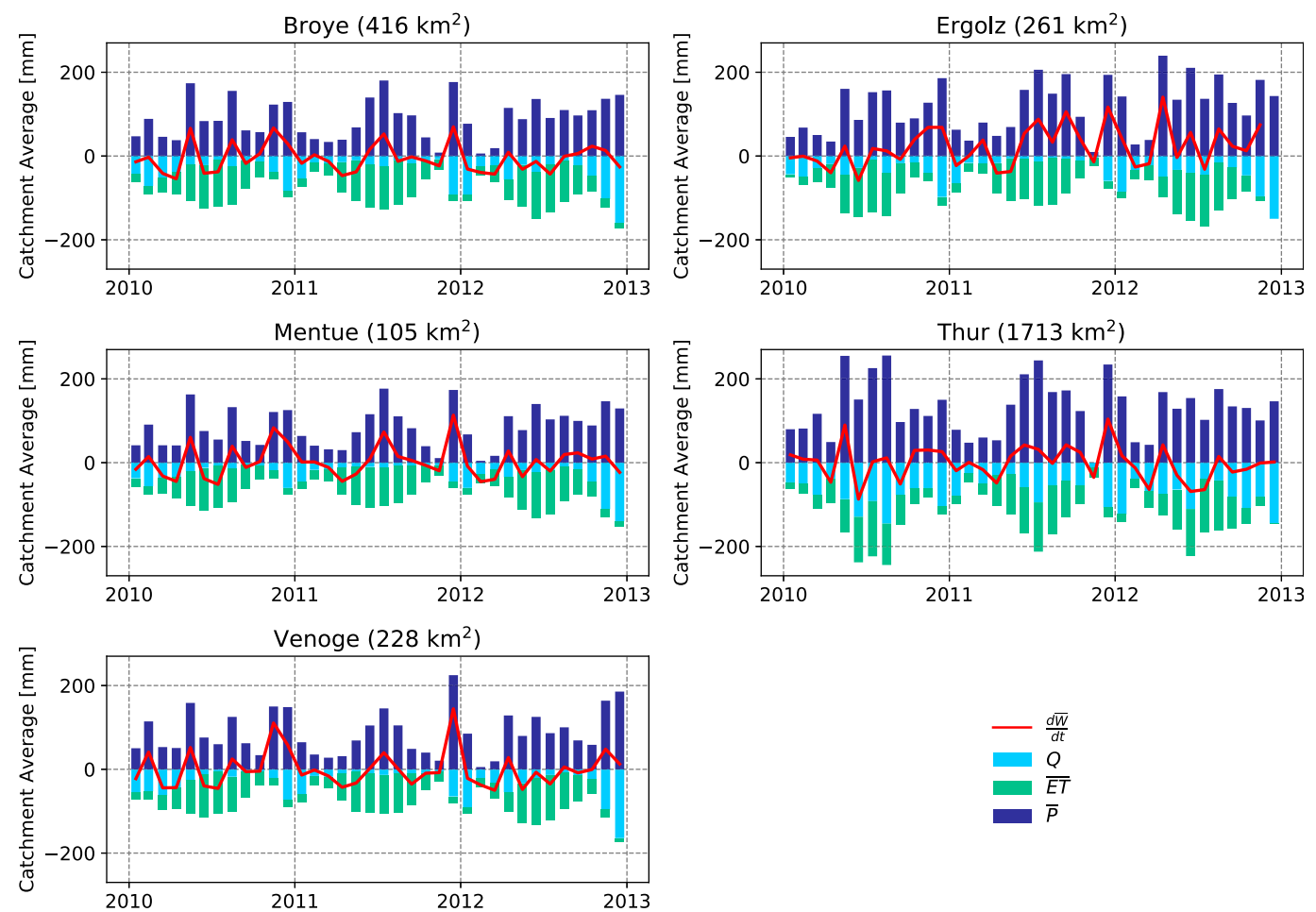

FIG. 3. Monthly catchment water balances as calculated from the validation data described in section $2 \mathrm{~b}$. COSMO-1 analyses for $\bar{P}$, FOEN river discharge measurements for $Q$, and MODIS MOD16A2 for $\overline{\mathrm{ET}}$. Storage change $d \bar{W} / d t$ is calculated as a residual.

Fig. 1b. Data are required first for forcing, second for validation and third for an uncertainty estimate.

Validation data are required for precipitation, river discharge and evapotranspiration in order to close the catchment water balance [Eq. (12)]. Data for precipitation and evapotranspiration are not available as direct measurements on the catchment scale, but rely on independent sets of modeling assumptions.

Note that the COSMO-1 analyses [see section $2 \mathrm{~b}(1)$ ] are used to force the TERRA ML standalone and to close the water budget in the validation approach. This is justified by the fact that the validation of precipitation is not a goal of this study.

\section{Results}

\section{a. Water balances}

Observation-derived water balances for the catchments considered can be found in Fig. 3. It shows all terms in Eq. (12) based on the validation data, i.e., COSMO-1 analyses for precipitation $\bar{P}$, FOEN data for river discharge $Q$, and MODIS for $\overline{\mathrm{ET}}$ and in addition, the implied storage changes $d \bar{W} / d t$. Generally, evapotranspiration follows an annual cycle with a maximum in July, while there is no evident annual cycle in precipitation. For the Broye, Ergolz, Mentue, and Venoge catchments located in the Swiss plateau, maxima in river discharge are found during the winter months, whereas for the Thur located partially in the Alps, the maxima in river discharge tend to occur during summer. This is likely a reflection of the higher mean elevation of the
Thur catchment, which leads to more snowfall instead of rain during the winter months. In all catchments, there are marked precipitation maxima in July 2011 and December 2011 while 2012 is the wettest year overall. Mean monthly contributions to the catchment water balance are summarized in Table 2. The mean inferred storage change is close to zero, except for the Ergolz catchment, where the mean implied storage change amounts to $23 \mathrm{~mm}$ month $^{-1}$, which is roughly one-fifth of mean monthly precipitation or one-third of mean monthly evapotranspiration. The major part of this imbalance seems to stem from the time period after spring 2011. The underlying reason for this imbalance is unclear.

\section{b. Observational uncertainty estimation}

\section{1) Estimation of $\Delta \bar{P}$}

The uncertainty of precipitation obtained from COSMO-1 analyses [section $2 b(1)$ ] is estimated using the rain gauge based monthly gridded dataset RhiresM [section 2b(2)]. Uncertainties for the individual catchments are calculated as RMSEs between the COSMO-1 analysis and RhiresM on monthly time intervals for the period 2010-12. Uncertainties for precipitation are estimated to range from $17.9 \mathrm{~mm} \mathrm{month}{ }^{-1}$ for the Broye catchment to $44.9 \mathrm{~mm} \mathrm{month}^{-1}$ for the Ergolz catchment (Fig. 4). Compared with the mean values for $\bar{P}$ (Table 2 ), the uncertainties correspond to relative uncertainties of $20 \%$ (for the Broye catchment) to $34 \%$ (for the Ergolz catchment). 
TABLE 2. Mean monthly contributions to the catchment water balance as estimated from the validation datasets for the period 2010-12. Storage change $d \bar{W} / d t$ is calculated as a residual from the right-hand side of Eq. (12).

\begin{tabular}{|c|c|c|c|c|c|}
\hline Variable & Broye & Ergolz & Mentue & Thur & Venoge \\
\hline $\bar{P}\left(\mathrm{~mm}\right.$ month $\left.^{-1}\right)$ & 89 & 117 & 84 & 131 & 86 \\
\hline$Q\left(\mathrm{~mm} \mathrm{month}^{-1}\right)$ & 38 & 37 & 29 & 60 & 33 \\
\hline ET $\left(\mathrm{mm}\right.$ month $\left.^{-1}\right)$ & 57 & 60 & 53 & 60 & 54 \\
\hline$d \bar{W} / d t\left(\mathrm{~mm} \mathrm{month}^{-1}\right)$ & -6 & 23 & 3 & -1 & 0 \\
\hline
\end{tabular}

\section{2) Estimation of $\Delta \overline{\mathrm{ET}}$}

The uncertainty of the MODIS MOD16A2 evapotranspiration product is estimated by calculating the RMSE between monthly values from FLUXNET eddy covariance evapotranspiration measurements [section $2 \mathrm{~b}(5)]$ and the respective nearest neighbor grid cell of the MODIS product. Monthly means of latent heat flux from FLUXNET sites are compared to monthly means of latent heat flux from the respective nearest neighbor in the MODIS evapotranspiration dataset [section $2 b(4)$ ]. The uncertainty in latent heat flux is then converted to an uncertainty in evapotranspiration using the latent heat of vaporization $\left(l_{V}=2.501 \times 10^{6} \mathrm{~J} \mathrm{~kg}^{-1}\right)$. Over all 10 considered FLUXNET stations (listed in appendix D, Table 6), a mean uncertainty of $21.6 \mathrm{~mm} \mathrm{month}^{-1}$ is estimated for the MODIS MOD16A2 evapotranspiration product (Fig. 4). Compared with the mean values for $\overline{\mathrm{ET}}$ (Table 2), the uncertainties correspond to relative uncertainties of $36 \%$ (for the Ergolz and Thur catchments) to $41 \%$ (for the Mentue catchment). Other (global) ET datasets have been evaluated using the procedure described above. The results and the rationale to choose the MODIS MOD16A2 product over other products for the subsequent analysis are discussed in appendix E.

\section{c. Application of the validation framework to TERRA ML}

Using the monthly catchment mass balances shown in Fig. 3 and the corresponding balances established from model output, it is possible to calculate monthly model errors. For each of the four model versions described in section $2 \mathrm{a}(2)$, monthly errors are calculated for catchment average runoff, catchment average evapotranspiration and catchment storage change and discussed subsequently

\section{1) Storage CHANGE}

Errors in storage change are shown in Fig. 5. The observational uncertainty is relatively large, and the errors lie mostly within the uncertainty. In all catchments, FLUXCORR and MOD perform relatively similar. Overall, the different runs do not seem to either gain or lose excessive amounts of water. Some features are nevertheless worth noting. SUPRESS seems to gain water toward the second half of 2012, which is also true for the other simulations, but there it lies mostly within the observational uncertainty. In the Broye, Mentue, and Ergolz catchments almost all model runs show negative errors during summer, which are, however, mostly within observational uncertainty. Note, that SUPPRESS shows a completely different behavior here, which could be a hint that this net loss of water is related to excessive surface runoff generation during convective rain events - a hypothesis that will be investigated in more detail in the next paragraph.

\section{2) RUNOFF}

Errors in catchment averaged runoff are shown in Fig. 6. By construction [Eq. (12)], monthly errors in storage change must be driven by either errors in catchment averaged runoff or evapotranspiration. When comparing the order of magnitude of the errors and the alignment of catchment averaged runoff (Fig. 6) and storage change errors (Fig. 5), it is very likely that errors in storage change are closely related to errors in runoff. Note that errors in evapotranspiration are considerably smaller (Fig. 7). To quantify the close relation between runoff errors and storage change errors, consider Table 3.

For all simulations and across all catchments, the correlation of storage change errors to catchment-averaged runoff errors is higher than the correlation of storage change errors to evapotranspiration errors and the difference in correlation is almost always substantial. A high correlation does not necessarily imply a causal relation between runoff errors and storage change errors. These errors could also be aligned due to errors in the precipitation data used to force the TERRA ML standalone.

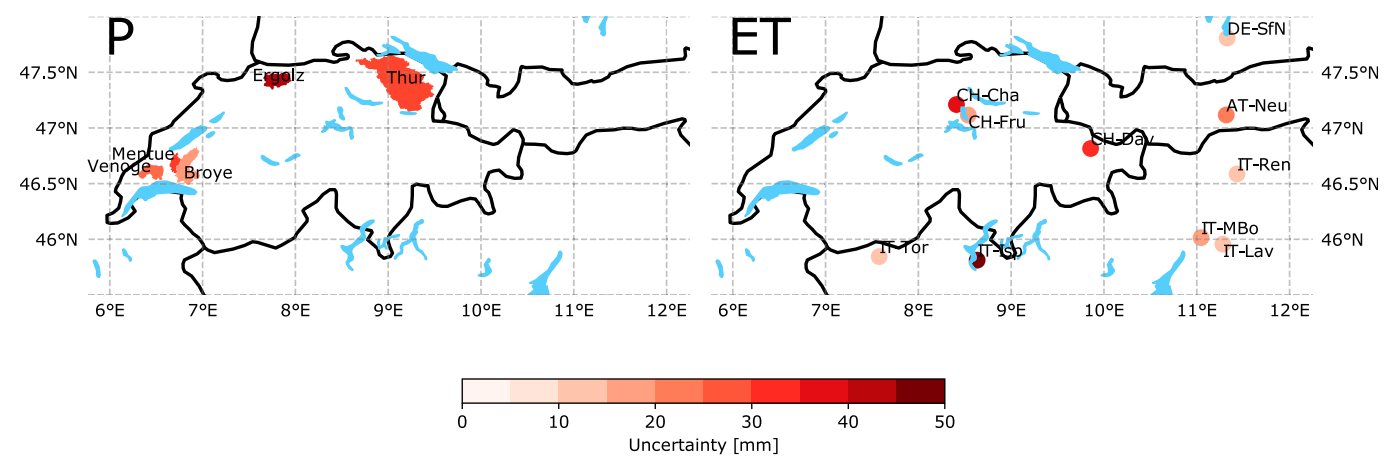

FIG. 4. Observational uncertainty estimates (COSMO-1 analyses-RhiresM) (left) for monthly precipitation at the selected catchments $(P)$ and (right) for evapotranspiration (MODIS-FLUXNET) at 10 FLUXNET stations in the Alpine region (ET). 

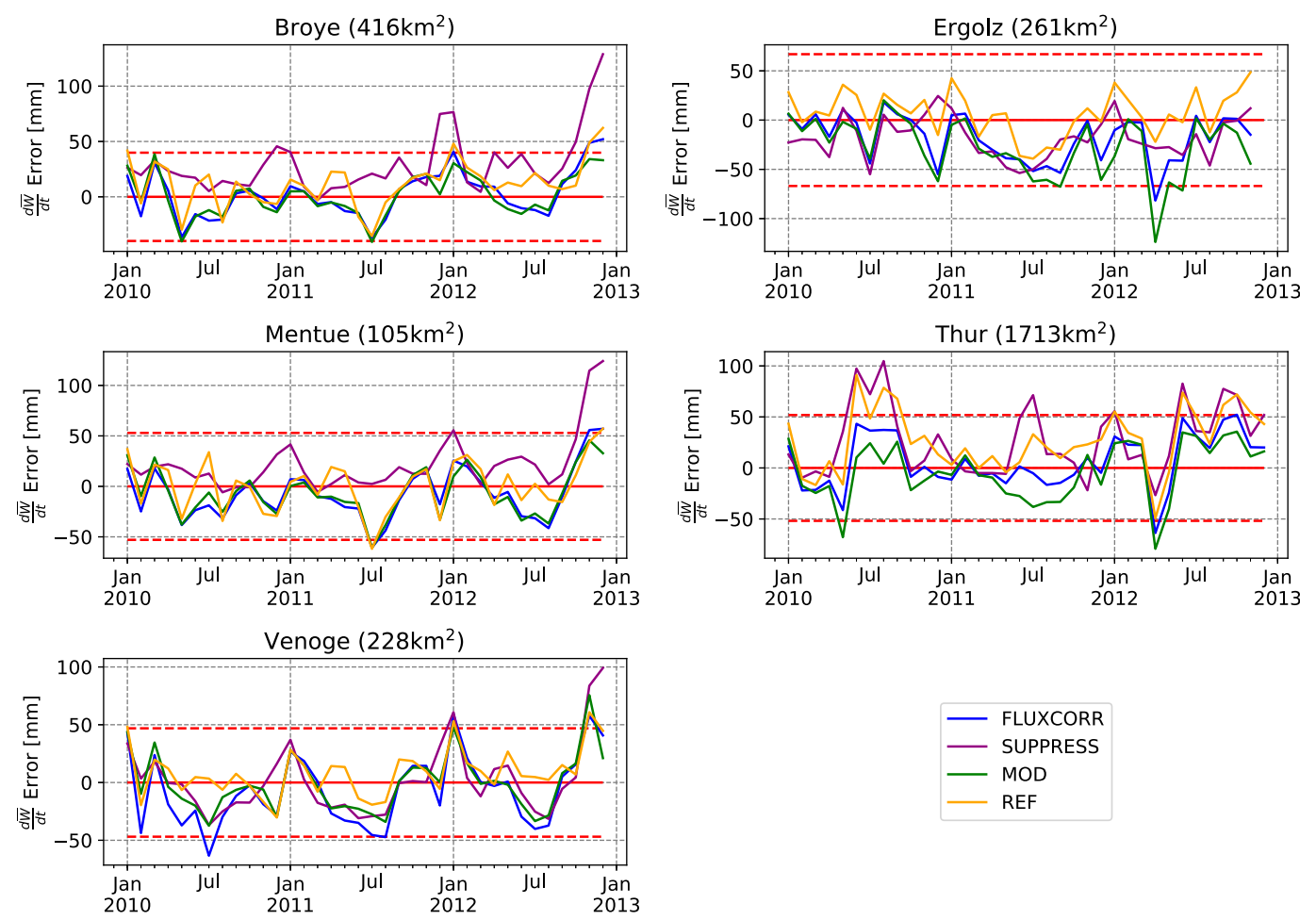

FIG. 5. Monthly errors in catchment averaged storage change $\left(\mathrm{mm} \mathrm{month}^{-1}\right)$ between the different model runs and the storage change as calculated from observations. The zero line is shown in solid red, and observational uncertainties are indicated by the dotted red lines.

However, the runoff error is often outside of its uncertainty range, which implies that errors in precipitation are most likely not the sole reason for the errors in runoff, as uncertainty in runoff is given by $\Delta \bar{P}$ (see section 3c). Therefore at least part of the runoff error stems from the formulation of surface and ground runoff in the model. Following section 3 , it is assumed that storage changes in the chosen catchments are roughly equivalent to soil water change. Errors in runoff generation either point to deficiencies in storage capacity or they themselves cause errors in soil water change and thus in available soil moisture for evapotranspiration. This in turn will cause errors in the annual cycle of evapotranspiration as evapotranspiration in TERRA ML is sensitive to soil moisture by construction [section 2a(1)]. Although often involving more processes, similar resistance formulations in plant water stress and bare soil evaporation can be found in other land surface models (Balsamo et al. 2009; Niu et al. 2011). Assuming that the sensitivity on soil moisture is correct, it will be hard or impossible to get accurate estimates of evapotranspiration without improving the representation of runoff generation and soil water storage capacity in land surface schemes.

As the implementations tested in this section target mainly runoff generation, model performance with respect to monthly catchment averaged runoff will be discussed a bit further. The observational uncertainty is narrower for runoff than for storage change, which allows for a few additional remarks at this point. Indeed, it seems that MOD and
FLUXCORR produce excessive runoff in the Broye, Ergolz, and Mentue catchments during summer. For the Broye and Mentue catchments, the same is true for REF, whereas in the Ergolz catchment, the observational uncertainty is too large to be certain. To illustrate the characteristics of the different simulations, time series of monthly runoff are shown in Fig. 8. For the neighboring Broye and Mentue catchments, the time series are similar and REF, MOD, and FLUXCORR all show a similar behavior-particularly during summer. Note that the free drainage ground runoff formulation in REF differs fundamentally from the one in MOD and FLUXCORR, which follows Schlemmer et al. (2018). In our simulations the major contribution to summer runoff in these two catchments stems from surface runoff which is subject to similar formulations of saturation excess and infiltration excess runoff generation for all simulations except SUPPRESS. This behavior is most pronounced in the Broye and Mentue catchments due to a relatively high clay fraction, which leads to higher amounts of surface runoff as the saturated hydraulic conductivity is low for clay (see appendix B for details). The fact that SUPPRESS does not show the same behavior in these catchments further supports this hypothesis. For the Thur and Ergolz catchments, the fraction of ground runoff is higher and therefore the formulation of ground runoff generation plays a more important role. For the Thur this is due to a combination of shallow water tables and high slope angles in the upper catchment (as expressed in $S_{\text {ORO }}$ for 

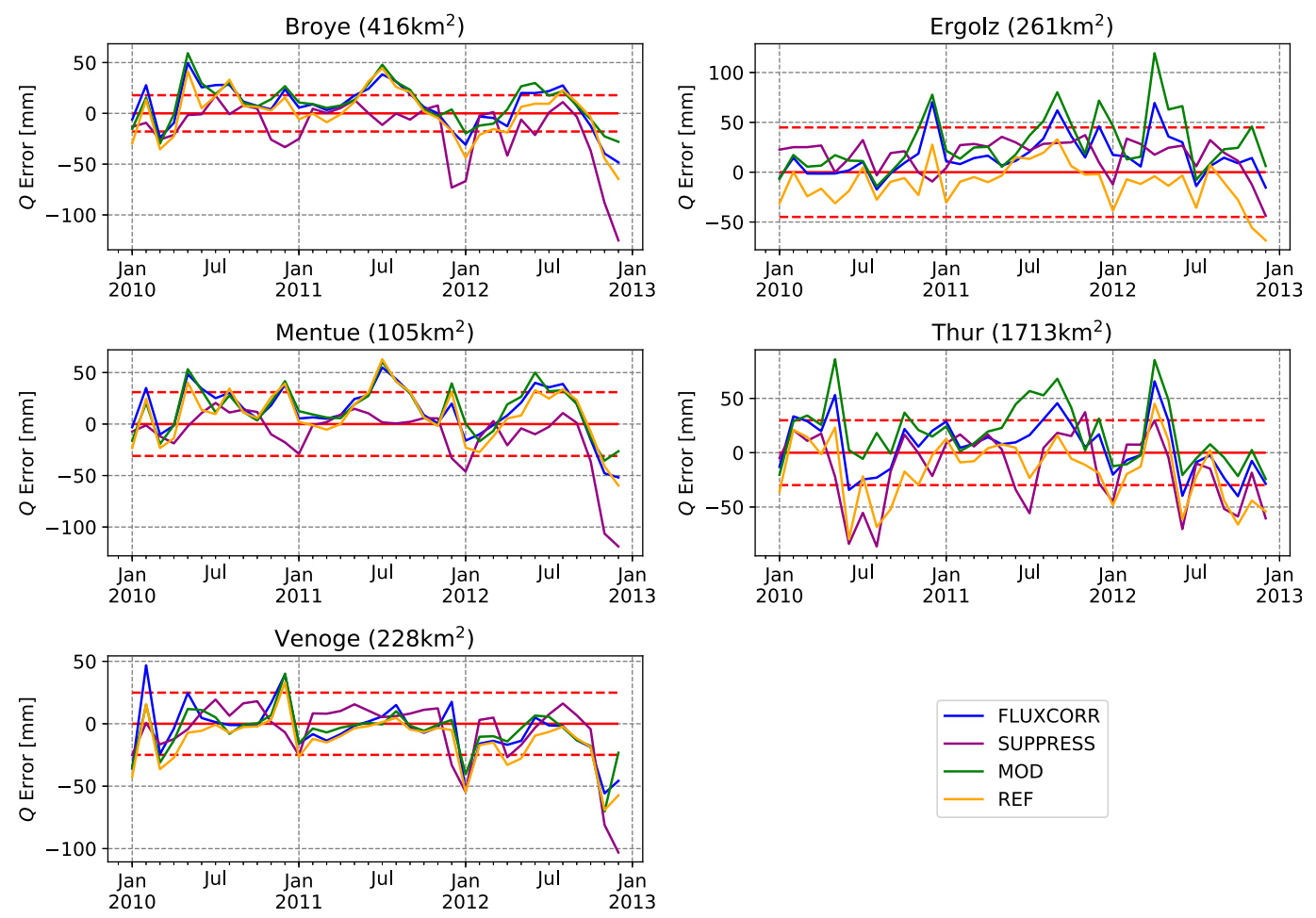

FIG. 6. Monthly errors in catchment averaged runoff $\left(\mathrm{mm} \mathrm{month}^{-1}\right)$ between the different model runs and catchment normalized discharge observations. The zero line is shown in solid red, and model uncertainty is indicated by the dotted red lines.

MOD, FLUXCORR, and SUPPRESS), for the Ergolz it is mostly due to relatively shallow water tables.

To condense the findings on runoff, Fig. 9 shows a normalized Taylor diagram for all 3-yr runs. The RMSE is relatively high, ranging from approximately $60 \%-90 \%$ of the observed standard deviation for REF, MOD, and FLUXCORR. For SUPPRESS the RMSE is even higher and exhibits a larger spread ranging from approximately $60 \%-110 \%$. The higher RMSE of SUPPRESS is associated with both a weaker correlation with the observations, as well as an underestimation of month-to-month variability as is expressed by the fact that the standard deviation of SUPPRESS is only around $70 \%$ of the observed standard deviation. This underestimation of standard deviation in SUPPRESS is probably caused by the lack of a mechanism to generate fast runoff.

\section{3) EVAPOTRANSPIRATION}

Due to the limitations mentioned in section $2 \mathrm{a}(3)$, evapotranspiration is shown for completeness only and in order to further demonstrate the analytic possibilities of the validation framework.

As REF is equivalent to the land surface scheme of the driving model (COSMO), it can be concluded from Fig. 7 with certainty that it generally underestimates evapotranspiration. This is particularly evident for the Thur and Broye catchments during summer. Notably, evapotranspiration is higher in the other model versions, but due to the lacking atmospheric feedback it is still unclear how large this effect would be in a coupled model. However, Schlemmer et al. (2018) show that MOD reduces summer warm bias in 2-m temperature in the Mediterranean region in coupled climate simulations. This is in line with higher evapotranspiration compared to REF.

\section{4) SUMMARY}

In summary, we find that storage change errors, and hence errors in soil water, are aligned with errors in catchment averaged runoff. This can at least partially be attributed to problems in the formulation of runoff generation. As the catchment budget must be closed at all times, this will inevitably lead to errors in evapotranspiration at some point. It is apparent from Figs. 6 and 8 that for some catchments runoff is consistently overestimated during summer, which is most likely attributable to the formulation of infiltration. Therefore, it is expected that significant improvements in the hydrological section of TERRA ML may be achieved by focusing on infiltration and the generation of surface runoff. In turn, a more accurate runoff scheme is a necessary precondition for a more accurate prediction of latent heat flux, which is ultimately one of the crucial variables the land surface scheme is supposed to feed back to the atmospheric model.

\section{Conclusions}

In this paper, we present a process-oriented framework to evaluate land surface schemes, which can be used to complement 

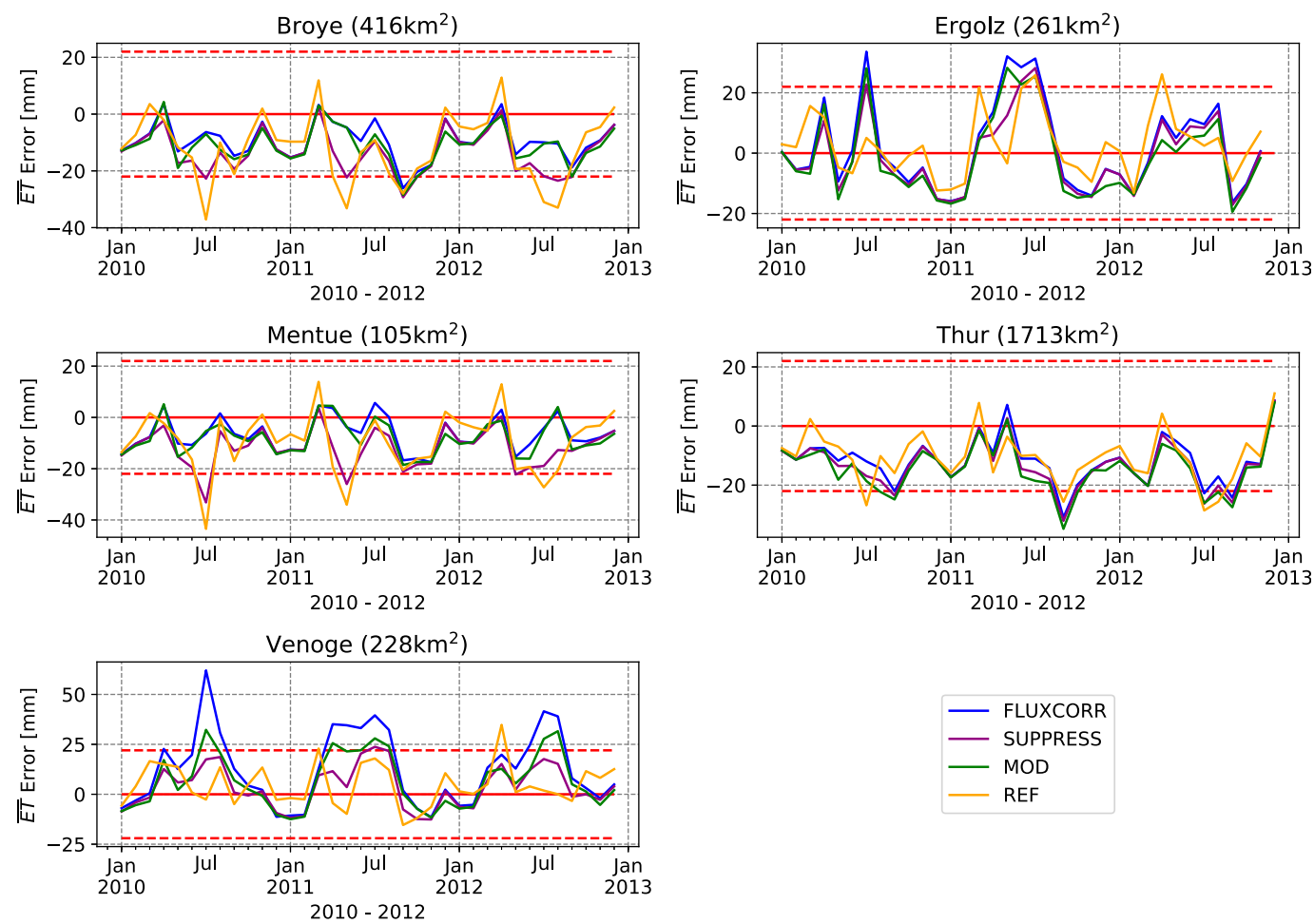

FIG. 7. Monthly errors ( $\mathrm{mm}$ month $^{-1}$ ) between catchment averaged ET from model runs and MODIS observations.

The zero line is shown in solid red, and observational uncertainty is indicated by the dotted red lines.

site-level validation based on eddy covariance measurements. While many processes in land surface modeling are not based on first principles, the catchment water balance [Eq. (12)] must hold and therefore it is a natural choice for the development of a validation strategy.

As operational NWP (Baldauf et al. 2011) and regional climate models (Leutwyler et al. 2017) have reached kilometer resolution and are depicting some of the hydrological processes fairly accurately, it is of growing importance to provide uncertainty estimates for the validation datasets. In practice it is still a challenge to compare observations, derived datasets, and models of different nominal resolutions to each other-to make optimal use of the observations for model evaluation. Here, we overcome this problem by aggregating data spatially over an area large enough that all employed datasets provide a reasonable source of information. At the same time, temporal aggregation ensures that further model assumptions (i.e., stream routing) are not required. These additional model assumptions could introduce further error cancellation effects and thus mask the errors we are aiming at identifying in the first place. Despite the sacrifice in spatiotemporal resolution and relatively large observational errors, we demonstrate that it is still possible to diagnose errors related to misrepresented processes in land surface schemes on the kilometer scale.

Usually the many interacting parts of NWP and climate models are tuned in order to optimize the results with respect to the quantities of interest. This is either done manually by model tuning, or increasingly by means of objective calibration methodologies (Bellprat et al. 2016; Voudouri et al. 2018), or by parameter estimation using data assimilation (e.g., Schirber et al. 2013). While this is certainly useful to yield the best possible performance of a given model for the task at hand, it

TABLE 3. Correlations of $Q$ and $\overline{\mathrm{ET}}$ errors to $d \bar{W} / d t$ errors of the respective model runs. Pearson correlation coefficients were calculated for the period 2010-12 on monthly time intervals.

\begin{tabular}{|c|c|c|c|c|c|c|c|c|c|c|}
\hline \multirow[b]{2}{*}{ Model } & \multicolumn{2}{|c|}{ Broye } & \multicolumn{2}{|c|}{ Ergolz } & \multicolumn{2}{|c|}{ Mentue } & \multicolumn{2}{|c|}{ Thur } & \multicolumn{2}{|c|}{ Venoge } \\
\hline & $Q$ & $\overline{\mathrm{ET}}$ & $Q$ & $\overline{\mathrm{ET}}$ & $Q$ & $\overline{\mathrm{ET}}$ & $Q$ & $\overline{\mathrm{ET}}$ & $Q$ & $\overline{\mathrm{ET}}$ \\
\hline FLUXCORR & -0.95 & -0.07 & -0.80 & -0.52 & -0.97 & -0.36 & -0.96 & -0.27 & -0.81 & -0.72 \\
\hline SUPPRESS & -0.97 & +0.31 & -0.83 & -0.77 & -0.97 & +0.10 & -0.97 & -0.25 & -0.94 & -0.52 \\
\hline MOD & -0.94 & -0.08 & -0.90 & -0.32 & -0.96 & -0.28 & -0.96 & -0.14 & -0.85 & -0.70 \\
\hline REF & -0.87 & +0.04 & -0.89 & -0.54 & -0.90 & -0.21 & -0.96 & -0.30 & -0.87 & -0.31 \\
\hline
\end{tabular}



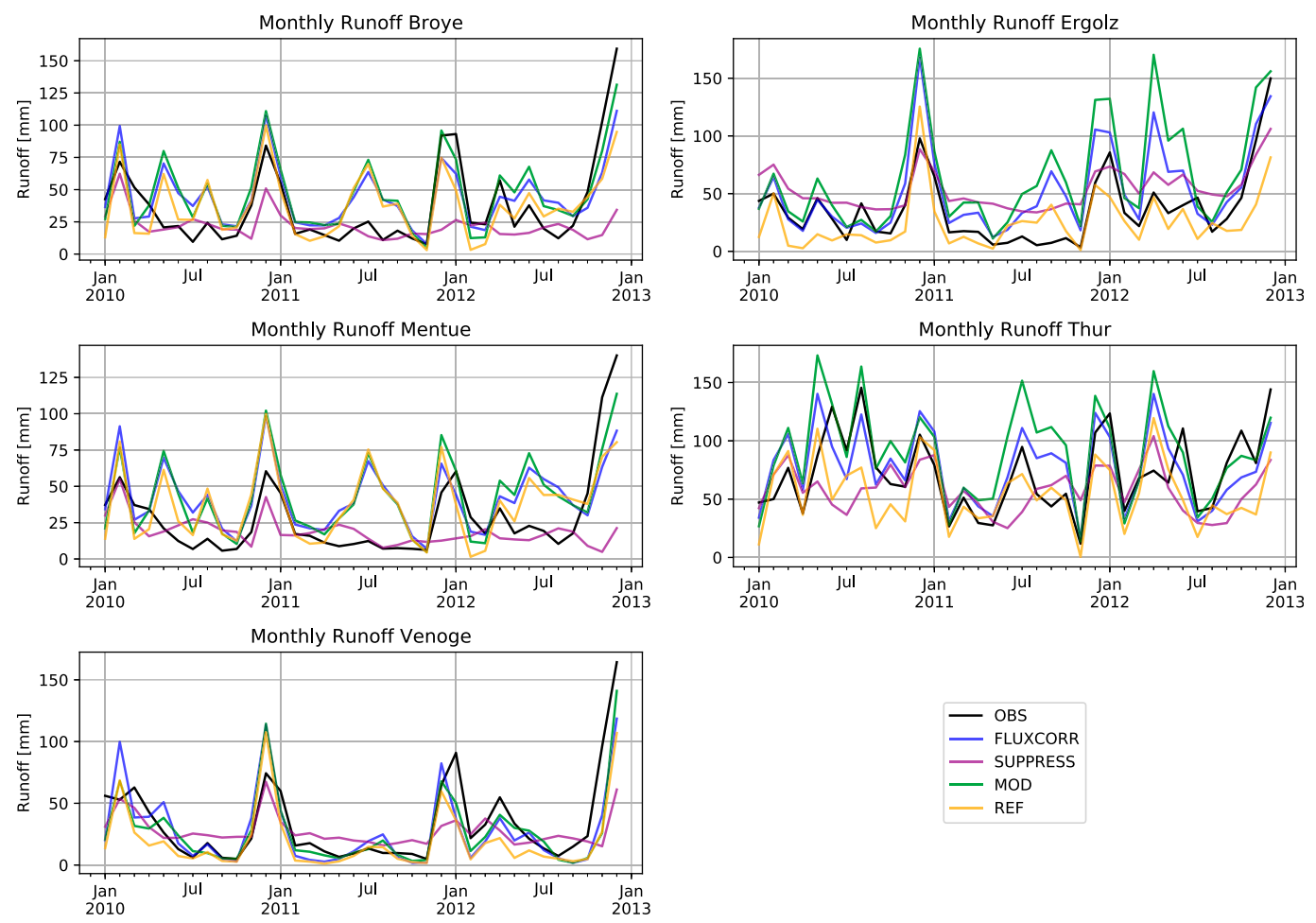

FIG. 8. Time series of monthly catchment averaged runoff from model runs FLUXCORR, SUPPRESS, MOD, REF (color lines), and observed discharge at the outlet OBS (black line).

hampers physically based model development. Usually any change implemented into a well-tuned model will decrease its skill, even if the respective change is well founded. In the case of land surface modeling, the situation is particularly problematic, as on the one hand, the NWP and climate modeling community is usually solely interested in having accurate estimates of the turbulent heat fluxes, and on the other hand our very limited (quantitative) knowledge often leads to equations with many unconstrained parameters. We therefore propose to use a process-oriented validation strategy in addition to the regular validation process for the validation of land surface models.

In the application to TERRA ML, we showed that using our framework helps to diagnose the misrepresentation of processes more decisively. First, we conclude that errors in storage change can to some part be attributed to errors in runoff. This is an important conclusion as it highlights the need to focus future work on TERRA ML (and likely other LSMs with similar hydrology parameterizations) to the runoff formation process. By design, errors in storage change will affect evapotranspiration. Second, it is clear that for runoff, model performance is highly dependent on the generation of fast runoff events, which are in turn related to the process of infiltration. The link between infiltration, runoff, storage change, and evapotranspiration would be hidden in a site-level evaluation of evapotranspiration.

In a next step, the presented framework could be used to objectively calibrate hydrological processes of the land surface model. Similarly, Mastrotheodoros et al. (2020) combine site-level evapotranspiration data from FLUXNET and river discharge measurements to calibrate their ecohydrological model and the validation shows positive results. Not only would this potentially improve the model, but if done for

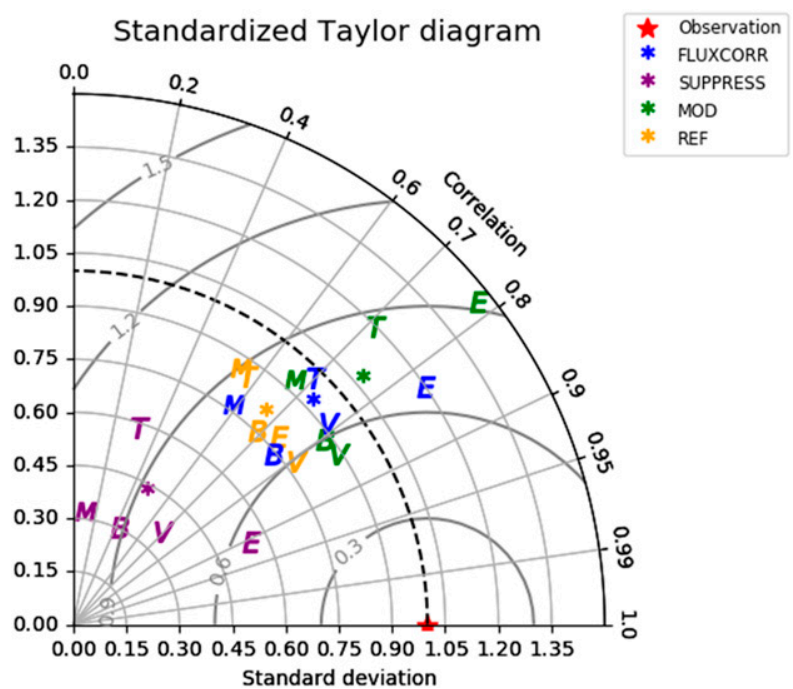

FIG. 9. Taylor diagram for monthly runoff. Modeled runoff was normalized with the standard deviation of the observed runoff of the respective catchment. The root-mean-square error is indicated by the gray solid circles. Individual catchments are depicted with their initial letter, and asterisks indicate average behavior over all catchments for the individual runs. The bold red star is the observation (reference). 
TABLE B1. Lookup table for soil hydraulic parameter in TERRA ML for soil types with active hydrology. For ice and rock the Richards equation is not solved, and rain and snowmelt are directly treated as surface runoff.

\begin{tabular}{|c|c|c|c|c|c|c|}
\hline & Sand & Sandy loam & Loam & Loamy clay & Clay & Peat \\
\hline Pore volume $\eta\left(\mathrm{m}^{3} \mathrm{~m}^{-3}\right)$ & 0.364 & 0.445 & 0.455 & 0.475 & 0.507 & 0.863 \\
\hline Field capacity $\theta_{\mathrm{FC}}\left(\mathrm{m}^{3} \mathrm{~m}^{-3}\right)$ & 0.196 & 0.260 & 0.340 & 0.370 & 0.463 & 0.763 \\
\hline Permanent wilting point $\theta_{w}\left(\mathrm{~m}^{3} \mathrm{~m}^{-3}\right)$ & 0.042 & 0.100 & 0.110 & 0.185 & 0.257 & 0.265 \\
\hline Air dryness point $\alpha_{\mathrm{dp}}\left(\mathrm{m}^{3} \mathrm{~m}^{-3}\right)$ & 0.012 & 0.030 & 0.035 & 0.060 & 0.065 & 0.098 \\
\hline Saturated hydraulic conductivity $K_{0}\left(10^{-9} \times \mathrm{m}^{2} \mathrm{~s}^{-1}\right)$ & 47900 & 9430 & 5310 & 764 & 17 & 58 \\
\hline Conductivity parameter $K_{1}$ & -19.27 & -20.86 & -19.66 & -18.52 & -16.32 & -16.48 \\
\hline Saturated hydraulic diffusivity $D_{0}\left(10^{-9} \times \mathrm{m}^{2} \mathrm{~s}^{-1}\right)$ & 18400 & 3460 & 3570 & 1180 & 442 & 106 \\
\hline Diffusivity parameter $D_{1}$ & -8.45 & -9.47 & -7.44 & -7.76 & -6.74 & -5.97 \\
\hline
\end{tabular}

multiple catchments, we would learn whether an optimal set of parameters is universal, or whether it depends strongly on the characteristics of the catchment. Furthermore, in order to assess what we can and should reasonably expect in terms
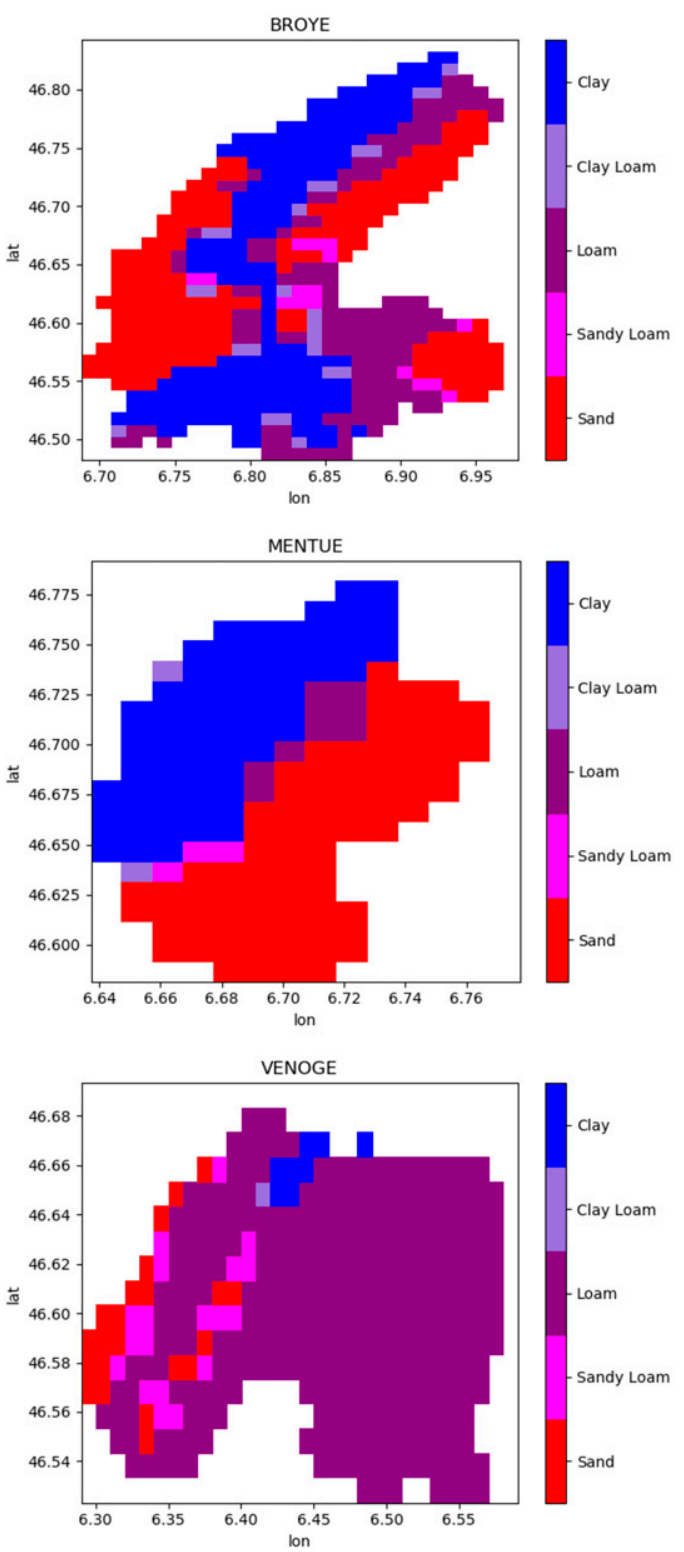

of predictive skill for river discharge, the validation framework could be used to benchmark a fully optimized land surface model against simple lumped hydrological models as, e.g., in Seibert et al. (2018).
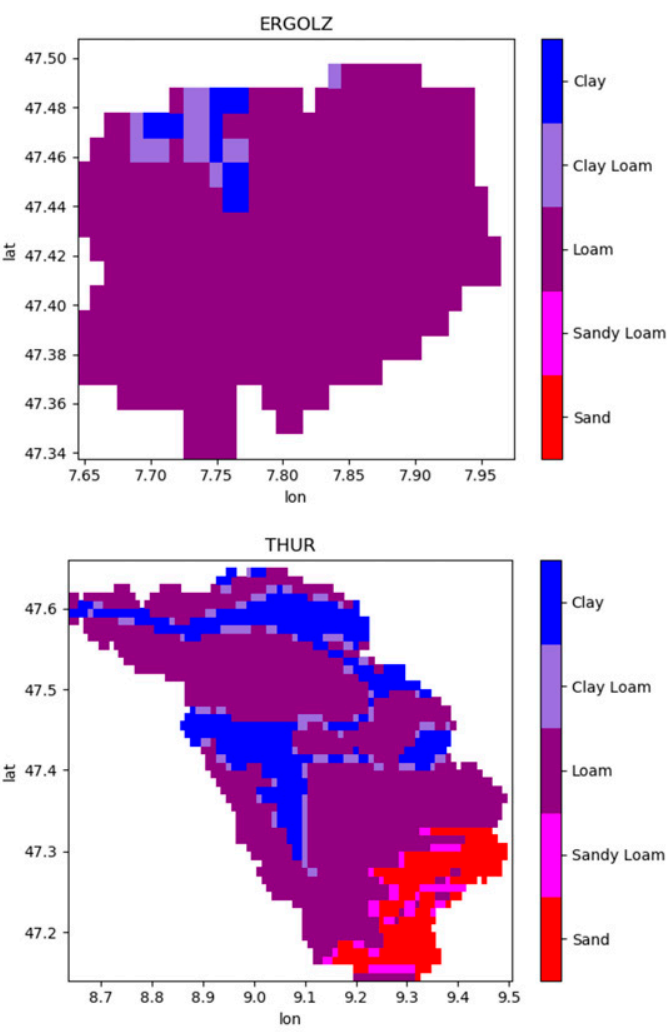

FIG. B1. Spatial distribution of soil type pixels for the validation catchments as used in TERRA ML for this study. 

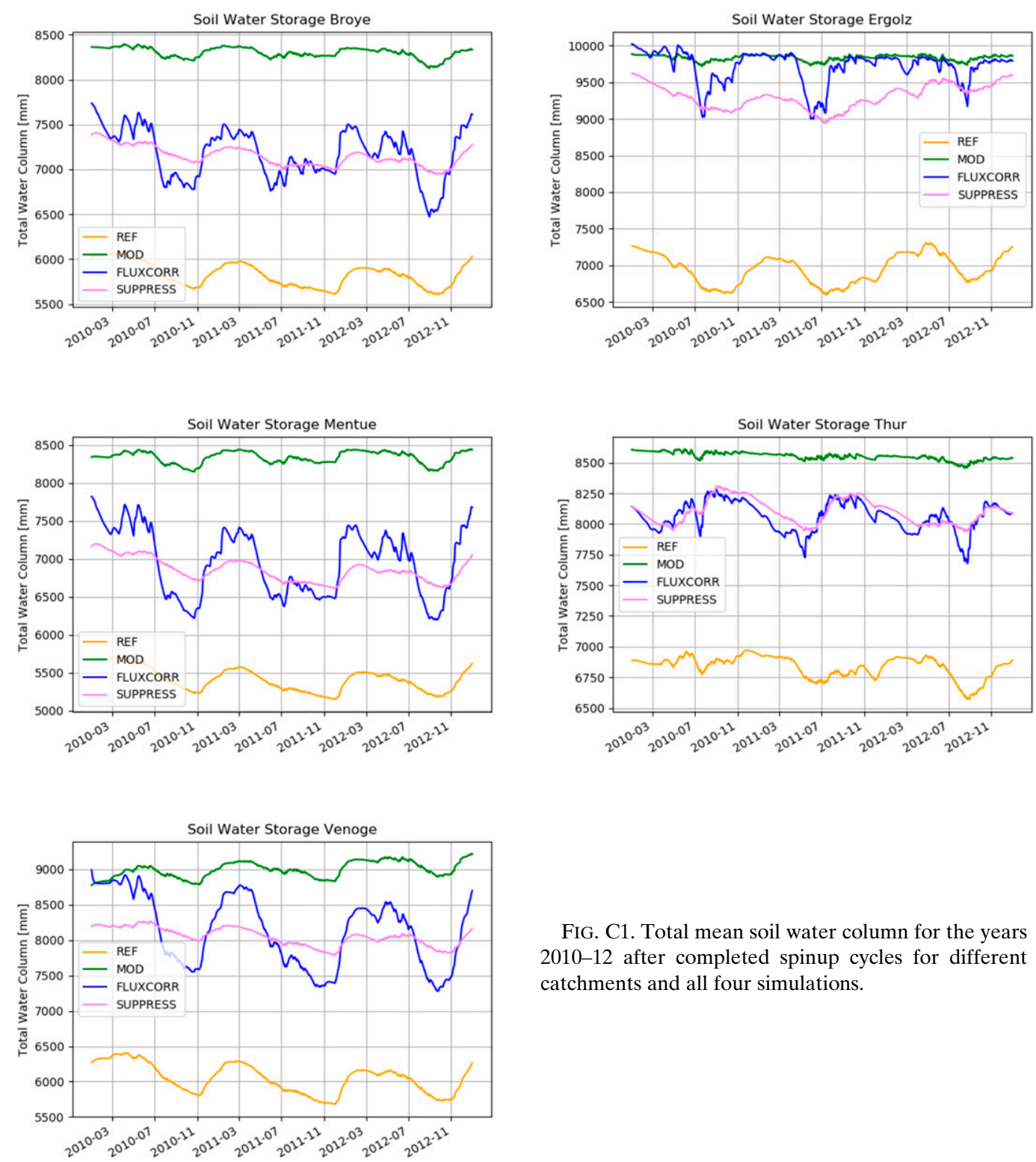

FIG. C1. Total mean soil water column for the years 2010-12 after completed spinup cycles for different catchments and all four simulations.

Acknowledgments. This work is funded by WEW COSMO, a collaboration of The Center for Climate Systems Modeling (C2SM) at ETH Zurich and MeteoSwiss.

We acknowledge a large number of datasets. This includes eddy covariance data acquired and shared by the FLUXNET

community (including the following networks: AmeriFlux, AfriFlux, AsiaFlux, CarboAfrica, CarboEuropeIP, CarboItaly, CarboMont, ChinaFlux, Fluxnet-Canada, GreenGrass, ICOS, KoFlux, LBA, NECC, OzFlux-TERN, TCOS-Siberia, and USCCC). The ERA-Interim reanalysis data are provided by

TABLE D1. Catchments chosen for model validation. Information provided by the Federal Office of Environment (https:// www.hydrodaten.admin.ch/en/current-situation-table-discharge-and-water-levels.html). Annual means are calculated from data described in section $2 b(3)$.

\begin{tabular}{llccc}
\hline \hline Catchment & Gauge station & Elevation (m MSL) (min, mean, max) & Area $\left(\mathrm{km}^{2}\right)$ & Annual mean discharge $(2010-17)\left(\mathrm{mm} \mathrm{yr}{ }^{-1}\right)$ \\
\hline Broye & Payerne & $427,615,1512$ & 416 & 525 \\
Ergolz & Liestal & $260,562,1163$ & 261 & 440 \\
Mentue & Yvonand & $428,661,926$ & 105 & 423 \\
Thur & Andelfingen & $345,755,2501$ & 1702 & 845 \\
Venoge & Ecublens & $371,685,1678$ & 228 & 469 \\
\hline
\end{tabular}


TABLE D2. List of FLUXNET 2015 sites used in this study. IGBP (International Geosphere-Biosphere Programme) Vegetation classes include grasslands (GRA), wetlands (WET), evergreen needle forests (ENF), and deciduous broadleaf (DBF) forests.

\begin{tabular}{llcll}
\hline \hline Station ID & \multicolumn{1}{c}{ Name } & Years used & IGBP & DOI \\
\hline AT-Neu & Neustift & $2010-12$ & GRA & $10.18140 /$ FLX/1440121 \\
CH-Cha & Chamau & $2010-14$ & GRA & $10.18140 /$FLX/1440131 \\
CH-Dav & Davos & $2010-14$ & ENF & $10.18140 /$ FLX/1440132 \\
CH-Fru & Früebüel & $2010-14$ & GRA & $10.18140 /$ FLX/1440133 \\
DE-Sfn & Schechenfilz Nord & $2012-14$ & WET & $10.18140 /$ FLX/1440219 \\
IT-Isp & ISPRA ABC-IS & $2013-14$ & ENF & $10.18140 /$ FLX/1440234 \\
IT-Lav & Lavarone & $2010-14$ & GRA & $10.18140 /$ FLX/1440169 \\
IT-Mbo & Monte Bondone & $2010-13$ & GRA & $10.18140 /$ FLX/1440170 \\
IT-Ren & Renon & GRA & $10.18140 /$ FLX/1440173 \\
IT-Tor & Torgnon & $2010-13$ & & $10.18140 /$ FLX/1440237 \\
\hline
\end{tabular}

ECMWF (European Centre for Medium-Range Weather Forecasts) and processed by LSCE (Le Laboratoire des Sciences du Climat et de l'Environnement). The FLUXNET eddy covariance data processing and harmonization was carried out by the European Fluxes Database Cluster, AmeriFlux Management Project, and Fluxdata project of FLUXNET, with the support of CDIAC and ICOS Ecosystem Thematic Center, and the OzFlux, ChinaFlux and AsiaFlux offices.

The authors also thank the Federal Office for the Environment (FOEN) for the streamflow measurement data and the Federal Office of Meteorology and Climatology MeteoSwiss for the gridded precipitation dataset RhiresM.

We thank André Walser, Daniel Leuenberger, Petra Baumann, Stefanie Westerhuis and Guy de Morsier for their technical assistance and Reto Stöckli for helpful comments on our work.

All simulations were carried out on the Piz Kesch/Tsa supercomputers located at the Swiss National Supercomputing Centre (CSCS, Lugano). The authors are grateful for the resources and support provided by MeteoSwiss as well as for the support provided by CSCS staff.

We thank reviewer 1 for his review, feedback, and the interesting discussions, and two anonymous reviewers for their constructive feedback on our manuscript.

Data availability statement. All datasets used in this study are publicly available. COSMO-1 analyses and RhiresM are available at MeteoSwiss upon request. Discharge measurements are available at the Federal Office for the Environment. These datasets are free of charge for universities/public research institutions. MODIS data are available at https:// lpdaac.usgs.gov/products/mod16a2v006/. The FLUXNET2015 dataset is available at https://fluxnet.org/data/fluxnet2015dataset/. Furthermore, Python packages built for catchmentbased validation are available from the corresponding author upon request.

\section{APPENDIX A}

\section{Short Description of the COSMO Model}

COSMO is a versatile modeling system used for operational NWP and for weather and climate research. The dynamical core solves the fully compressible Euler equations discretized with a fifth-order upwind scheme for horizontal advection and a Crank-Nicolson scheme for vertical advection (Baldauf et al. 2011). The forward integration is done using a split-explicit three stage second-order Runge-Kutta solver (Wicker and Skamarock 2002; Klemp and Wilhelmson 1978). Microphysical processes are treated in a single-moment bulk scheme with five hydrometeor classes (cloud water, cloud ice, rain, snow, and graupel) (Reinhardt and Seifert 2006) and radiation in a radiative transfer scheme based on the $\delta$-two-stream approach (Ritter and Geleyn 1992). Turbulent exchange in the surface layer and the boundary layer is parameterized with a turbulent kinetic energy-based 1.5-order turbulence closure (Mellor and Yamada 1982; Raschendorfer et al. 2003). The land surface scheme TERRA ML (Heise et al. 2003) is introduced in section $2 \mathrm{a}$.

\section{APPENDIX B}

\section{Soil Hydraulic Parameter and Vegetation Properties}

In TERRA ML, the hydraulic fluxes within the soil column are parameterized following Rijtema (1969). Hydraulic conductivity is given by

$$
K(\theta)=K_{0} \exp \left(K_{1} \frac{\theta-\alpha_{\mathrm{DP}}}{\theta_{\mathrm{FC}}-\alpha_{\mathrm{DP}}}\right),
$$

and hydraulic diffusivity is given by

$$
D(\theta)=D_{0} \exp \left(D_{1} \frac{\theta-\alpha_{\mathrm{DP}}}{\theta_{\mathrm{FC}}-\alpha_{\mathrm{DP}}}\right)
$$

These functions are sensitive to volumetric soil moisture $\theta$ and a number of mostly hard-coded parameter that depend on the soil type at a given grid point, which are given in Table B1. The spatial distribution of soil types is obtained from the FAO harmonized world soil database (FAO et al. 2012) and for the catchments considered in this study, the distribution of soil types is shown in Fig. B1.

Vegetation is treated in a very simplistic fashion in TERRA ML [see Doms et al. (2011) for a detailed description]. Most 

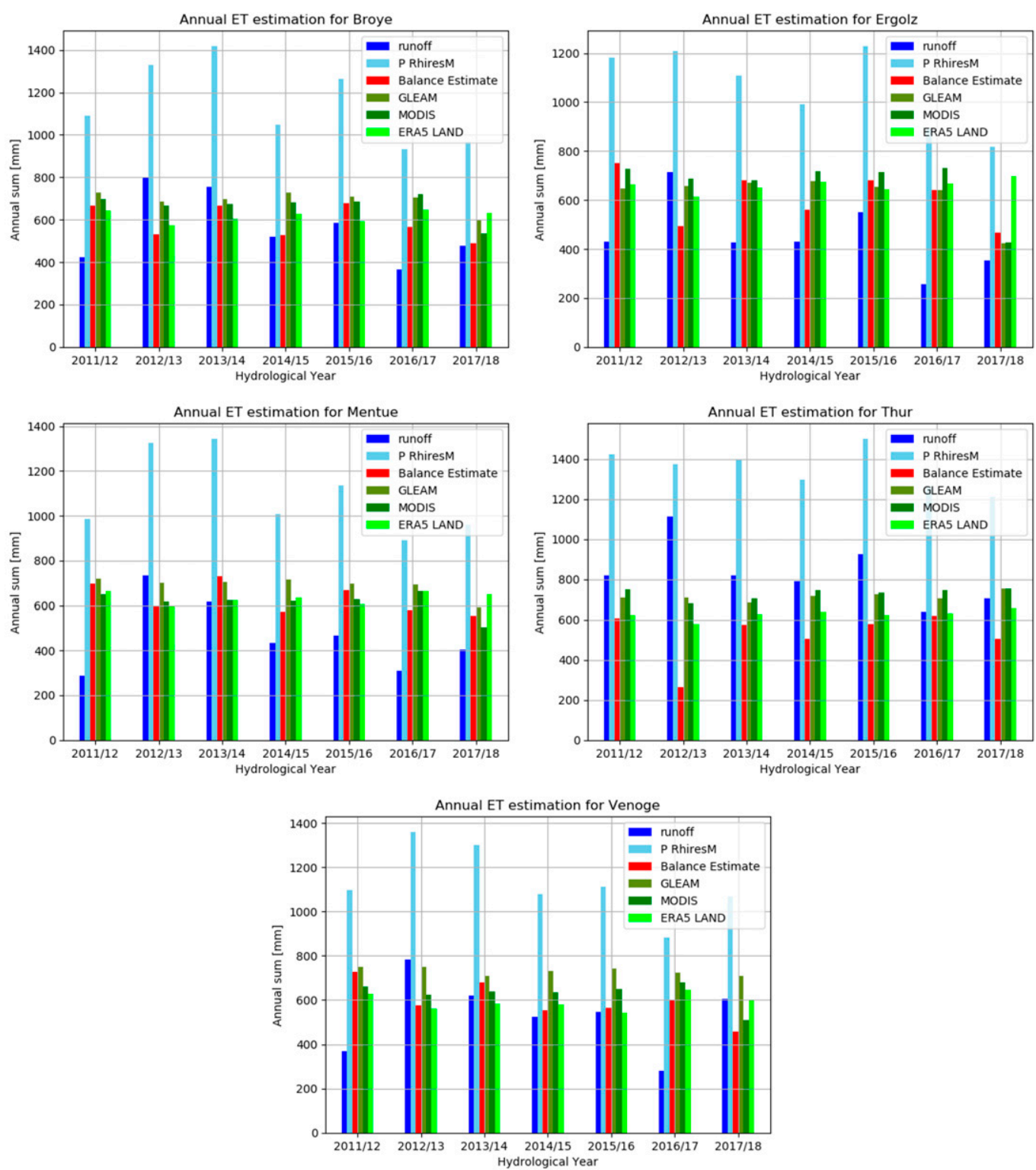

FIG. E1. Comparison of different evapotranspiration datasets. Catchment precipitation, runoff, balance estimate ET (difference between precipitation and runoff), and product estimate ET for all investigated catchments for the ERA5-Land, GLEAM, and MODIS MOD16A2 evapotranspiration products in the validation catchments.

second and third generation LSMs infer surface albedo from the vegetation state (Pitman 2003). However, for TERRA ML, this is not the case as surface albedo is a function of soil type and soil moisture content, with the former relation being prescribed by external parameter fields. Root zone depth is prescribed through a further external parameter field and ranges predominantly from 0.6 to $1.0 \mathrm{~m}$ for all catchments considered in this study. Similarly, leaf area index is interpolated between prescribed fields for minimum values during winter and maximum values during the growth season. More details on the generation of external parameter fields for COSMO (and hence TERRA ML) are given in Schättler and Blahak (2018).

\section{APPENDIX C}

\section{Spinup Procedure}

COSMO-1 analyses are available for the years 2010-12 [see section $2 \mathrm{~b}(1)]$. The analyses are used to force the standalone version of TERRA ML. However, the model versions MOD, FLUXCORR, and SUPPRESS deviate substantially from $\mathrm{REF}$, which is also used in the coupled model. Therefore, the equilibrium state of the land surface will be different (i.e., for soil moisture) and the corresponding runs require a proper spinup period. For MOD, FLUXCORR, and SUPPRESS, the bottom layer $(7.29-21.8 \mathrm{~m})$ is filled to saturation at the 
TABLE E1. Mean annual ET for the different ET products and as estimated from catchment balances for the period 2010-18. Relative errors of the ET products are given with respect to the results from the balance estimates.

\begin{tabular}{|c|c|c|c|c|c|}
\hline ET dataset & Broye & Ergolz & Mentue & Thur & Venoge \\
\hline ERA5 Land ( $\left.\mathrm{mm} \mathrm{yr}^{-1}\right)$ & 617 & 659 & 634 & 625 & 592 \\
\hline $\operatorname{GLEAM}\left(\mathrm{mm} \mathrm{yr}^{-1}\right)$ & 693 & 624 & 688 & 714 & 731 \\
\hline MODIS $\left(\mathrm{mm} \mathrm{yr}^{-1}\right)$ & 665 & 669 & 615 & 730 & 628 \\
\hline Balance estimate $\left(\mathrm{mm} \mathrm{yr}^{-1}\right)$ & 589 & 610 & 628 & 521 & 595 \\
\hline Relative difference ERA5 (\%) & 7 & 11 & 2 & 29 & 1 \\
\hline Relative difference GLEAM (\%) & 19 & 4 & 10 & 48 & 25 \\
\hline Relative difference MODIS (\%) & 14 & 11 & -1 & 50 & 7 \\
\hline
\end{tabular}

initialization before spinup such as to start with a water table. Then the years 2010-12 are cycled twice for the simulation with MOD, FLUXCORR, and SUPPRESS, respectively. For REF the situation is different as it is already in equilibrium with the forcing data. Therefore the simulation with REF is cycled once to bring it to the same initial state as the other three simulations. Figure $\mathrm{C} 1$ shows the change in total water column. For all catchments, the total water column exhibits almost no longterm trends but pronounced annual cycles. Given this result, it is assumed that all simulations are sufficiently equilibrated.

\section{APPENDIX D}

\section{Supporting Geographical Information}

A summary of geographical and hydrological properties of the validation catchments is given in Table D1.

Ten FLUXNET stations in the vicinity of the validation catchments are chosen for the uncertainty estimation (section $4 b$ ). The location of the stations is indicated by station ID in Fig. 4. In addition, the most important properties as well as the corresponding references are presented in Table D2.

\section{APPENDIX E}

\section{Comparison of Different ET Products}

Evapotranspiration products based on the Priestley-Taylor equation such as GLEAM (Martens et al. 2017) and PT-JPL (Fisher et al. 2008) have been shown to outperform PenmanMonteith type algorithms (Miralles et al. 2016; Michel et al. 2016). Furthermore, with ERA-5 Land (Copernicus Climate Change Service 2019), there exists an alternative global dataset of relatively high resolution based on a state-of-the-art land surface model and assimilated meteorological data. The longterm performance of the aforementioned evapotranspiration datasets is checked using Eq. (13) as introduced in section 3a. RhiresM is used for catchment aggregated precipitation $\bar{P}$ [section $2 \mathrm{~b}(2)$ ] and the FOEN measurements are used for river discharge $Q$ [section $2 \mathrm{~b}(3)$ ]. As highlighted in section 3a, this approach is valid for time scales longer than approximately one year. To avoid artifacts due to snowfall/snowmelt, we estimate evapotranspiration over hydrological years. In Switzerland, a hydrological year is defined to range from 1 November to 31 October of the subsequent year. Figure E1 shows precipitation, river discharge and estimated evapotranspiration next to product evapotranspiration for the validation catchments. A summary of these results is shown in Table E1, which shows mean annual evapotranspiration averaged over the period 2010-18. Generally, evapotranspiration is overestimated by all investigated products, with an overall better agreement of ERA5-Land with the estimated catchment evapotranspiration. Interestingly, for all products, the performance in the Thur catchment is clearly worse than in the other catchments. The reasons are unclear, and it may not be excluded that RhiresM underestimates precipitation in the Thur catchment, which would also lead to the observed discrepancies [as can be seen from Eq. (13)]. Note that the Thur catchment is also the most alpine of all validation catchments (Table D1 and Fig. 2a).

Given that the mean relative errors of all products are in a similar range (Table E1), the MODIS MOD16A2 product is chosen as a validation dataset for this study, because the spatial resolution of its vegetation state $(500 \mathrm{~m})$ best matches the footprint of site-level data from flux towers. Therefore, an uncertainty estimation based on site-level data will be more meaningful than for the other datasets.

\section{REFERENCES}

Abramowitz, G., R. Leuning, M. Clark, and A. Pitman, 2008: Evaluating the performance of land surface models. J. Climate, 21, 5468-5481, https://doi.org/10.1175/2008JCLI2378.1.

Baldauf, M., A. Seifert, J. Förstner, D. Majewski, M. Raschendorfer, and T. Reinhardt, 2011: Operational convective-scale numerical weather prediction with the COSMO model: Description and sensitivities. Mon. Wea. Rev., 139, 3887-3905, https://doi.org/ 10.1175/MWR-D-10-05013.1.

Balsamo, G., A. Beljaars, K. Scipal, P. Viterbo, B. van den Hurk, M. Hirschi, and A. K. Betts, 2009: A revised hydrology for the ECMWF model: Verification from field site to terrestrial water storage and impact in the integrated forecast system. J. Hydrometeor., 10, 623-643, https://doi.org/10.1175/ 2008JHM1068.1.

Ban, N., and Coauthors, 2021: The first multi-model ensemble of regional climate simulations at kilometer-scale resolution, Part I: Evaluation of precipitation. Climate Dyn., 57, 275-302, https://doi.org/10.1007/s00382-021-05708-w.

Beljaars, A. C., P. Viterbo, M. J. Miller, and A. K. Betts, 1996: The anomalous rainfall over the United States during July 1993: Sensitivity to land surface parameterization and soil moisture anomalies. Mon. Wea. Rev., 124, 362-383, https://doi.org/ 10.1175/1520-0493(1996)124<0362:TAROTU >2.0.CO;2.

Bellprat, O., S. Kotlarski, D. Lüthi, R. De Elía, A. Frigon, R. Laprise, and C. Schär, 2016: Objective calibration of regional climate models: Application over Europe and North 
America. J. Climate, 29, 819-838, https://doi.org/10.1175/ JCLI-D-15-0302.1.

Beven, K., and P. Germann, 1982: Macropores and water flow in soils. Water Resour. Res., 18, 1311-1325, https://doi.org/10.1029/ WR018i005p01311.

Bierdel, L., P. Friederichs, and S. Bentzien, 2012: Spatial kinetic energy spectra in the convection-permitting limited-area NWP model COSMO-DE. Meteor. Z., 21, 245-258, https:// doi.org/10.1127/0941-2948/2012/0319.

Boris, J. P., and D. L. Book, 1973: Flux-corrected transport. I. Shasta, a fluid transport algorithm that works. J. Comput. Phys., 11, 38-69, https://doi.org/10.1016/0021-9991(73)90147-2.

Brooks, R. H., and A. T. Corey, 1966: Properties of porous media affecting fluid flow. J. Irrig. Drain. Div., 92, 61-88, https:// doi.org/10.1061/JRCEA4.0000425.

Burstedde, C., J. A. Fonseca, and S. Kollet, 2018: Enhancing speed and scalability of the ParFlow simulation code. Comput. Geosci., 22, 347-361, https://doi.org/10.1007/s10596-017-9696-2.

Cai, X., Z.-L. Yang, C. H. David, G.-Y. Niu, and M. Rodell, 2014: Hydrological evaluation of the Noah-MP land surface model for the Mississippi River basin. J. Geophys. Res. Atmos., 119, 23-38, https://doi.org/10.1002/2013JD020792.

Chaney, N. W., J. K. Roundy, J. E. Herrera-Estrada, and E. F. Wood, 2015: High-resolution modeling of the spatial heterogeneity of soil moisture: Applications in network design. Water Resour. Res., 51, 619-638, https://doi.org/10.1002/ 2013WR014964.

Chen, T. H., and Coauthors, 1997: Cabauw experimental results from the Project for Intercomparison of Land-Surface Parameterization Schemes. J. Climate, 10, 1194-1215, https:// doi.org/10.1175/1520-0442(1997)010<1194:CERFTP>2.0.CO;2.

Copernicus Climate Change Service, 2019: C3S ERA5-land reanalysis. Copernicus Climate Change Service, https://doi.org/ 10.24381/cds.68d2bb30.

Cuntz, M., J. Mai, L. Samaniego, M. Clark, V. Wulfmeyer, O. Branch, S. Attinger, and S. Thober, 2016: The impact of standard and hard-coded parameters on the hydrologic fluxes in the Noah-MP land surface model. J. Geophys. Res. Atmos., 121, 10 676-10 700, https://doi.org/10.1002/2016JD025097.

Decharme, B., H. Douville, A. Boone, F. Habets, and J. Noilhan, 2006: Impact of an exponential profile of saturated hydraulic conductivity within the ISBA LSM: Simulations over the Rhône basin. J. Hydrometeor., 7, 61-80, https://doi.org/10.1175/ JHM469.1.

Dirmeyer, P. A., and S. Halder, 2016: Sensitivity of numerical weather forecasts to initial soil moisture variations in CFSv2. Wea. Forecasting, 31, 1973-1983, https://doi.org/10.1175/ WAF-D-16-0049.1.

Doms, G., and Coauthors, 2011: A Description of the Nonhydrostatic Regional COSMO Model. Part II: Physical Parameterization. Deutscher Wetterdienst, 27 pp., http://www.cosmo-model.org/ content/model/documentation/core/cosmo_physics_4.20.pdf.

Entekhabi, D., and Coauthors, 1999: An agenda for land surface hydrology research and a call for the second international hydrological decade. Bull. Amer. Meteor. Soc., 80, 2043-2058, https://doi.org/10.1175/1520-0477(1999)080<2043:AAFLSH> 2.0.CO;2.

FAO, IIASA, ISRIC, ISSCAS, and JRC, 2012: Harmonized World Soil Database (version 1.2). FAO and IIASA, http:// webarchive.iiasa.ac.at/Research/LUC/External-World-soildatabase/HTML/index.html?sb=1.

Fischer, E. M., S. I. Seneviratne, P. L. Vidale, D. Lüthi, and C. Schär, 2007: Soil moisture-atmosphere interactions during the 2003 European summer heat wave. J. Climate, 20, 50815099, https://doi.org/10.1175/JCLI4288.1.

Fisher, J. B., K. P. Tu, and D. D. Baldocchi, 2008: Global estimates of the land-atmosphere water flux based on monthly AVHRR and ISLSCP-II data, validated at 16 FLUXNET sites. Remote Sens. Environ., 112, 901-919, https://doi.org/ 10.1016/j.rse.2007.06.025

FOEN, 2021: River discharge data. Federal Office for the Environment, accessed 17 February 2021, https://www.bafu.admin.ch/bafu/ en/home/topics/water/state/data/obtaining-monitoring-data-onthe-topic-of-water/hydrological-data-service-for-watercoursesand-lakes.html.

Foken, T., 2008: The energy balance closure problem: An overview. Ecol. Appl., 18, 1351-1367, https://doi.org/10.1890/060922.1.

Frei, C., and C. Schär, 1998: A precipitation climatology of the Alps from high-resolution rain-gauge observations. Int. J. Climatol., 18, 873-900, https://doi.org/10.1002/(SICI)1097-0088(19980630) 18:8<873::AID-JOC255>3.0.CO;2-9.

- , and J. Schmidli, 2006: Das Niederschlagsklima der Alpen: Wo sich Extreme nahe kommen. Promet, 32, 61-67.

Gulden, L. E., E. Rosero, Z.-L. Yang, M. Rodell, C. S. Jackson, G.-Y. Niu, P. J.-F. Yeh, and J. Famiglietti, 2007: Improving land-surface model hydrology: Is an explicit aquifer model better than a deeper soil profile? Geophys. Res. Lett., 34, L09402, https://doi.org/10.1029/2007GL029804.

Haughton, N., and Coauthors, 2016: The plumbing of land surface models: Is poor performance a result of methodology or data quality? J. Hydrometeor., 17, 1705-1723, https://doi.org/ 10.1175/JHM-D-15-0171.1.

Heise, E., M. Lange, B. Ritter, and R. Schrodin, 2003: Improvement and validation of the multi-layer soil model. COSMO Newsletter, No. 3, Consortium for Small-Scale Modeling, Offenbach, Germany, 198-203, http://www.cosmo-model.org/content/model/ documentation/newsLetters/newsLetter03/cnl3-chp9-12.pdf.

Hirschi, M., P. Viterbo, and S. I. Seneviratne, 2006: Basin-scale water-balance estimates of terrestrial water storage variations from ECMWF operational forecast analysis. Geophys. Res. Lett., 33, L21401, https://doi.org/10.1029/2006GL027659.

Hohenegger, C., P. Brockhaus, C. S. Bretherton, and C. Schär, 2009: The soil moisture-precipitation feedback in simulations with explicit and parameterized convection. J. Climate, 22, 5003-5020, https://doi.org/10.1175/2009JCLI2604.1.

Imamovic, A., L. Schlemmer, and C. Schär, 2017: Collective impacts of orography and soil moisture on the soil moistureprecipitation feedback. Geophys. Res. Lett., 44, 11 682-11691, https://doi.org/10.1002/2017GL075657.

Jarvis, P., 1976: The interpretation of the variations in leaf water potential and stomatal conductance found in canopies in the field. Philos. Trans. Roy. Soc. London, 273, 593-610, https:// doi.org/10.1098/rstb.1976.0035.

Klemp, J. B., and R. B. Wilhelmson, 1978: The simulation of threedimensional convective storm dynamics. J. Atmos. Sci., 35, 1070-1096, https://doi.org/10.1175/1520-0469(1978)035<1070: TSOTDC $>2.0 . \mathrm{CO} ; 2$.

Koster, R. D., Z. Guo, R. Yang, P. A. Dirmeyer, K. Mitchell, and M. J. Puma, 2009: On the nature of soil moisture in land surface models. J. Climate, 22, 4322-4335, https://doi.org/10.1175/ 2009JCLI2832.1.

—, S. D. Schubert, A. M. DeAngelis, A. M. Molod, and S. P. Mahanama, 2020: Using a simple water balance framework to quantify the impact of soil moisture initialization on subseasonal evapotranspiration and air temperature forecasts. 
J. Hydrometeor., 21, 1705-1722, https://doi.org/10.1175/JHMD-20-0007.1.

Lawrence, D. M., and Coauthors, 2019: The community land model version 5: Description of new features, benchmarking, and impact of forcing uncertainty. J. Adv. Model. Earth Syst., 11, 4245-4287, https://doi.org/10.1029/2018MS001583.

Leutwyler, D., D. Lüthi, N. Ban, O. Fuhrer, and C. Schär, 2017: Evaluation of the convection-resolving climate modeling approach on continental scales. J. Geophys. Res. Atmos., 122, 5237-5258, https://doi.org/10.1002/2016JD026013.

— , A. Imamovic, and C. Schär, 2021: The continental-scale soil moisture-precipitation feedback in Europe with parameterized and explicit convection. J. Climate, 34, 5303-5320, https:// doi.org/10.1175/JCLI-D-20-0415.1.

Louis, J.-F., 1979: A parametric model of vertical eddy fluxes in the atmosphere. Bound.-Layer Meteor., 17, 187-202, https:// doi.org/10.1007/BF00117978.

Manabe, S., J. Smagorinsky, and R. F. Strickler, 1965: Simulated climatology of a general circulation model with a hydrologic cycle. Mon. Wea. Rev., 93, 769-798, https://doi.org/10.1175/ 1520-0493(1965)093<0769:SCOAGC $>2.3$.CO;2.

Martens, B., and Coauthors, 2017: Gleam v3: Satellite-based land evaporation and root-zone soil moisture. Geosci. Model Dev., 10, 1903-1925, https://doi.org/10.5194/gmd-10-1903-2017.

Mastrotheodoros, T., and Coauthors, 2020: More green and less blue water in the Alps during warmer summers. Nat. Climate Change, 10, 155-161, https://doi.org/10.1038/s41558-019-0676-5.

Maxwell, R. M., and S. J. Kollet, 2008: Interdependence of groundwater dynamics and land-energy feedbacks under climate change. Nat. Geosci., 1, 665-669, https://doi.org/10.1038/ ngeo315.

— , F. K. Chow, and S. J. Kollet, 2007: The groundwater-landsurface-atmosphere connection: Soil moisture effects on the atmospheric boundary layer in fully-coupled simulations. Adv. Water Resour., 30, 2447-2466, https://doi.org/10.1016/ j.advwatres.2007.05.018.

Mellor, G. L., and T. Yamada, 1982: Development of a turbulence closure model for geophysical fluid problems. Rev. Geophys., 20, 851-875, https://doi.org/10.1029/RG020i004p00851.

MeteoSwiss, 2016: Documentation of MeteoSwiss grid-data products: Monthly and yearly precipitation: RhiresM and RhiresY. MeteoSwiss Tech. Rep., Federal Office for Meteorology and Climatology, 4 pp., https://www.meteoswiss.admin.ch/content/ dam/meteoswiss/de/service-und-publikationen/produkt/raeumlichedaten-niederschlag/doc/ProdDoc_RhiresM.pdf.

Michel, D., and Coauthors, 2016: The WACMOS-ET project Part 1: Tower-scale evaluation of four remote-sensing-based evapotranspiration algorithms. Hydrol. Earth Syst. Sci., 20, 803-822, https://doi.org/10.5194/hess-20-803-2016.

Miralles, D. G., and Coauthors, 2016: The WACMOS-ET projectpart 2: Evaluation of global terrestrial evaporation data sets. Hydrol. Earth Syst. Sci., 20, 823-842, https://doi.org/10.5194/ hess-20-823-2016.

Mu, Q., M. Zhao, and S. W. Running, 2011: Improvements to a MODIS global terrestrial evapotranspiration algorithm. Remote Sens. Environ., 115, 1781-1800, https://doi.org/10.1016/ j.rse.2011.02.019.

Mueller, B., and S. I. Seneviratne, 2012: Hot days induced by precipitation deficits at the global scale. Proc. Natl. Acad. Sci. USA, 109, 12398-12 403, https://doi.org/10.1073/pnas.1204330109.

Niu, G.-Y., and Coauthors, 2011: The community Noah land surface model with multiparameterization options (NoahMP): 1. Model description and evaluation with local-scale measurements. J. Geophys. Res., 116, D12109, https://doi.org/ 10.1029/2010JD015139.

Pastorello, G., and Coauthors, 2020: The FLUXNET2015 dataset and the ONEFlux processing pipeline for eddy covariance data. Sci. Data, 7, 225, https://doi.org/10.1038/s41597-020-0534-3.

Penman, H. L., 1948: Natural evaporation from open water, bare soil and grass. Proc. Roy. Soc. London, 193, 120-145, https:// doi.org/10.1098/rspa.1948.0037.

Pielke, R. A., Sr., 2001: Influence of the spatial distribution of vegetation and soils on the prediction of cumulus convective rainfall. Rev. Geophys., 39, 151-177, https://doi.org/10.1029/ 1999RG000072.

Pitman, A. J., 2003: The evolution of, and revolution in, land surface schemes designed for climate models. Int. J. Climatol., 23, 479-510, https://doi.org/10.1002/joc.893.

Prentice, I. C., X. Liang, B. E. Medlyn, and Y.-P. Wang, 2015: Reliable, robust and realistic: The three R's of next-generation land-surface modelling. Atmos. Chem. Phys., 15, 5987-6005, https://doi.org/ 10.5194/acp-15-5987-2015.

Raschendorfer, M., C. Simmer, and P. Gross, 2003: Parameterisation of turbulent transport in the atmosphere. Dynamics of Multiscale Earth Systems, Springer, 167-185.

Reinhardt, T., and A. Seifert, 2006: A three-category ice scheme for LMK. Cosmo Newsletter, No. 6, Consortium for SmallScale Modeling, Offenbach, Germany, 115-120, http:// www.cosmo-model.org/content/model/documentation/newsLetters/ newsLetter06/cnl6_reinhardt.pdf.

Richards, L. A., 1931: Capillary conduction of liquids through porous mediums. Physics, 1, 318-333, https://doi.org/10.1063/ 1.1745010 .

Rihani, J. F., F. K. Chow, and R. M. Maxwell, 2015: Isolating effects of terrain and soil moisture heterogeneity on the atmospheric boundary layer: Idealized simulations to diagnose land-atmosphere feedbacks. J. Adv. Model. Earth Syst., 7, 915-937, https://doi.org/ 10.1002/2014MS000371.

Rijtema, P., 1969: Soil moisture forecasting, instituut voor cultuurtechniek en waterhuishouding. Tech. Rep. Nota 513, 30 pp., https://edepot.wur.nl/188174.

Ritter, B., and J.-F. Geleyn, 1992: A comprehensive radiation scheme for numerical weather prediction models with potential applications in climate simulations. Mon. Wea. Rev., 120, 303-325, https://doi.org/10.1175/1520-0493(1992)120<0303: ACRSFN $>2.0 . \mathrm{CO} ; 2$.

Running, S. W., Q. Mu, M. Zhao, and A. Moreno, 2017: Modis Global Terrestrial Evapotranspiration (ET) Product (NASA MOD16A2/A3) NASA Earth Observing System MODIS Land Algorithm. User's Guide, NASA, 34 pp., https:// ladsweb.modaps.eosdis.nasa.gov/missions-and-measurements/ modis/MOD16_ET_User-Guide_2017.pdf

Schär, C., P. L. Vidale, D. Lüthi, C. Frei, C. Häberli, M. A. Liniger, and C. Appenzeller, 2004: The role of increasing temperature variability in European summer heatwaves. Nature, 427, 332336, https://doi.org/10.1038/nature02300.

Schättler, U., and U. Blahak, 2018: A description of the nonhydrostatic regional COSMO model. Part V: Initial and boundary data for the COSMO-Model. Deutscher Wetterdienst, 58 pp., https:// www.dwd.de/EN/ourservices/cosmo_documentation/pdf_docu_ v5_0/5_int2lm_2_00.pdf?_blob $=$ publicationFile \&v $=3$.

Schirber, S., D. Klocke, R. Pincus, J. Quaas, and J. L. Anderson, 2013: Parameter estimation using data assimilation in an atmospheric general circulation model: From a perfect toward the real world. J. Adv. Model. Earth Syst., 5, 58-70, https:// doi.org/10.1029/2012MS000167. 
Schlemmer, L., C. Schär, D. Lüthi, and L. Strebel, 2018: A groundwater and runoff formulation for weather and climate models. J. Adv. Model. Earth Syst., 10, 1809-1832, https:// doi.org/10.1029/2017MS001260.

Schraff, C., and R. Hess, 2003: A description of the nonhydrostatic regional model LM. Part III: Data assimilation. COSMO, 85 pp., https://www.dwd.de/SharedDocs/downloads/ EN/model_description/nwp/lm_parts/lm_docu_3_ass_200306_ en.html.

Schulz, J.-P., and G. Vogel, 2017: An improved representation of the land surface temperature including the effects of vegetation in the COSMO model. Geophysical Research Abstracts, Vol. 19, Abstract 7896, https://meetingorganizer.copernicus.org/ EGU2017/EGU2017-7896.pdf.

— scheme TERRA: Bare soil evaporation and skin temperature. Atmosphere, 11, 513, https://doi.org/10.3390/atmos11050513.

Schumacher, D. L., J. Keune, C. C. Van Heerwaarden, J. V.-G. de Arellano, A. J. Teuling, and D. G. Miralles, 2019: Amplification of mega-heatwaves through heat torrents fuelled by upwind drought. Nat. Geosci., 12, 712-717, https://doi.org/10.1038/ s41561-019-0431-6.

Seibert, J., M. J. Vis, E. Lewis, and H. V. Meerveld, 2018: Upper and lower benchmarks in hydrological modelling. Hydrol. Processes, 32, 1120-1125, https://doi.org/10.1002/hyp.11476.

Seneviratne, S. I., T. Corti, E. L. Davin, M. Hirschi, E. B. Jaeger, I. Lehner, B. Orlowsky, and A. J. Teuling, 2010: Investigating soil moisture-climate interactions in a changing climate: A review. Earth-Sci. Rev., 99, 125-161, https://doi.org/10.1016/ j.earscirev.2010.02.004.

Sevruk, B., 1985: Correction of precipitation measurements summary report. Correction of Precipitation Measurements, Swiss Federal Institute of Technology, 141-145.

Skamarock, W. C., 2004: Evaluating mesoscale NWP models using kinetic energy spectra. Mon. Wea. Rev., 132, 3019-3032, https://doi.org/10.1175/MWR2830.1.

Stephan, K., S. Klink, and C. Schraff, 2008: Assimilation of radarderived rain rates into the convective-scale model COSMODE at DWD. Quart. J. Roy. Meteor. Soc., 134, 1315-1326, https://doi.org/10.1002/qj.269.

Stöckli, R., P. L. Vidale, A. Boone, and C. Schär, 2007: Impact of scale and aggregation on the terrestrial water exchange: Integrating land surface models and Rhone catchment observations. J. Hydrometeor., 8, 1002-1015, https://doi.org/ 10.1175/JHM613.1.

Taylor, C. M., C. E. Birch, D. J. Parker, N. Dixon, F. Guichard, G. Nikulin, and G. M. Lister, 2013: Modeling soil moistureprecipitation feedback in the Sahel: Importance of spatial scale versus convective parameterization. Geophys. Res. Lett., 40, 6213-6218, https://doi.org/10.1002/2013GL058511.
Vereecken, H., R. Kasteel, J. Vanderborght, and T. Harter, 2007: Upscaling hydraulic properties and soil water flow processes in heterogeneous soils: A review. Vadose Zone J., 6, 1-28, https:// doi.org/10.2136/vzj2006.0055.

Vidale, P. L., D. Lüthi, R. Wegmann, and C. Schär, 2007: European summer climate variability in a heterogeneous multi-model ensemble. Climatic Change, 81, 209-232, https://doi.org/ 10.1007/s10584-006-9218-z.

Viterbo, P., and A. C. Beljaars, 1995: An improved land surface parameterization scheme in the ECMWF model and its validation. J. Climate, 8, 2716-2748, https://doi.org/10.1175/15200442(1995)008<2716:AILSPS>2.0.CO;2.

Voudouri, A., P. Khain, I. Carmona, E. Avgoustoglou, P. Kaufmann, F. Grazzini, and J. Bettems, 2018: Optimization of high resolution COSMO model performance over Switzerland and Northern Italy. Atmos. Res., 213, 70-85, https://doi.org/ 10.1016/j.atmosres.2018.05.026.

Weingartner, R., 1989: Application of the unit hydrograph model to Swiss catchments. IAHS Publ., 193, 669-676.

Western, A. W., R. B. Grayson, and G. Blöschl, 2002: Scaling of soil moisture: A hydrologic perspective. Ann. Rev. Earth Planet. Sci., 30, 149-180, https://doi.org/10.1146/ annurev.earth.30.091201.140434.

Weusthoff, T., F. Ament, M. Arpagaus, and M. W. Rotach, 2010: Assessing the benefits of convection-permitting models by neighborhood verification: Examples from MAP D-PHASE. Mon. Wea. Rev., 138, 3418-3433, https://doi.org/10.1175/ 2010MWR3380.1.

Wicker, L. J., and W. C. Skamarock, 2002: Time-splitting methods for elastic models using forward time schemes. Mon. Wea. Rev., 130, 2088-2097, https://doi.org/10.1175/1520-0493(2002) 130<2088:TSMFEM $>2.0$. CO;2.

Zalesak, S. T., 1979: Fully multidimensional flux-corrected transport algorithms for fluids. J. Comput. Phys., 31, 335-362, https://doi.org/10.1016/0021-9991(79)90051-2.

Zhao, M., F. A. Heinsch, R. R. Nemani, and S. W. Running, 2005: Improvements of the MODIS terrestrial gross and net primary production global data set. Remote Sens. Environ., 95, 164176, https://doi.org/10.1016/j.rse.2004.12.011.

- , S. W. Running, and R. R. Nemani, 2006: Sensitivity of moderate resolution imaging spectroradiometer (MODIS) terrestrial primary production to the accuracy of meteorological reanalyses. J. Geophys. Res., 111, G01002, https:// doi.org/10.1029/2004JG000004.

Zhou, X., J. Polcher, T. Yang, Y. Hirabayashi, and T. NguyenQuang, 2018: Understanding the water cycle over the upper Tarim basin: Retrospect the estimated discharge bias to atmospheric variables and model structure. Hydrol. Earth Syst. Sci., 22, 6087-6108, https://doi.org/10.5194/hess-226087-2018. 